تحليل كينماتبكية تكنيك سباحي \& × × إم حرة بلوزة المغرب

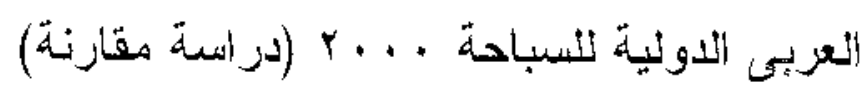

* د./ مددوح محمد الثشناويى

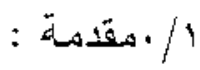

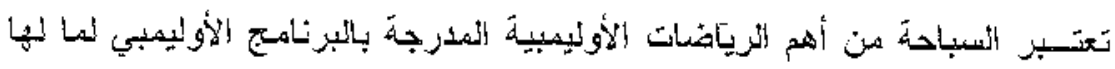

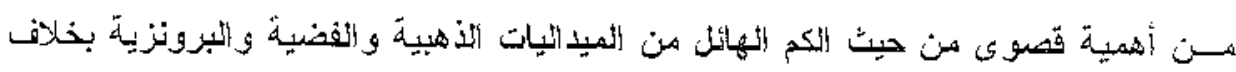

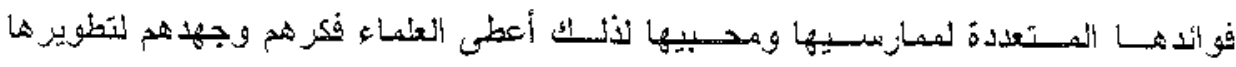

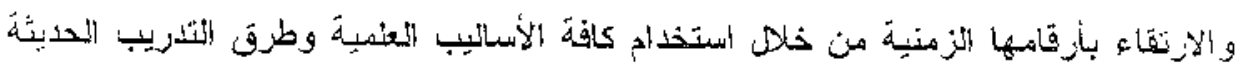

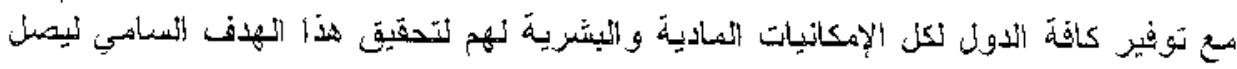

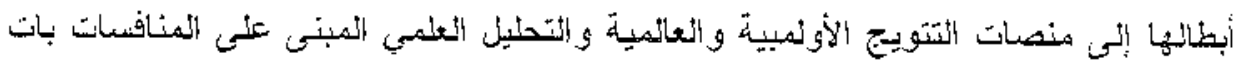

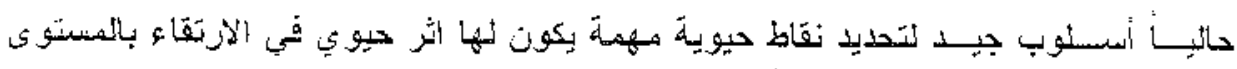

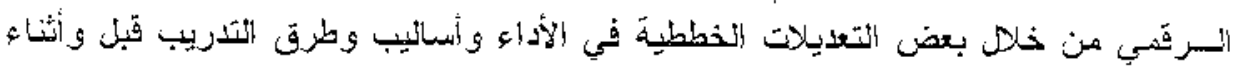

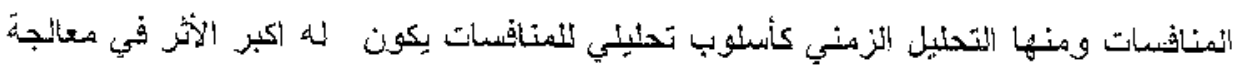

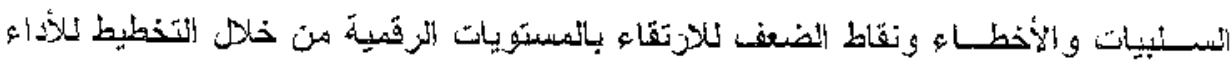

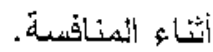

\title{
: 1/9
}

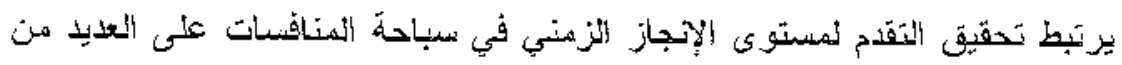

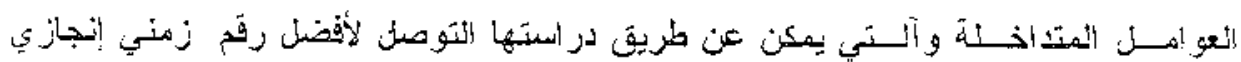

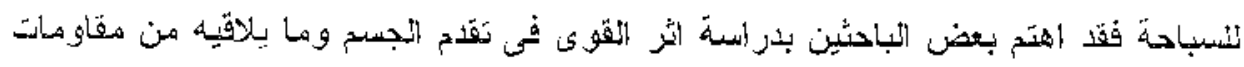

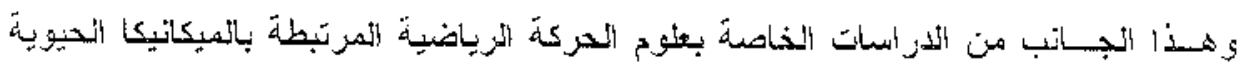

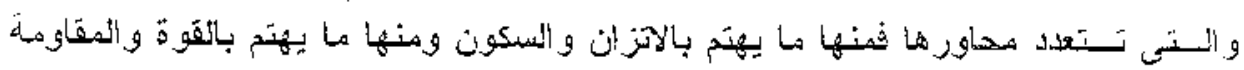

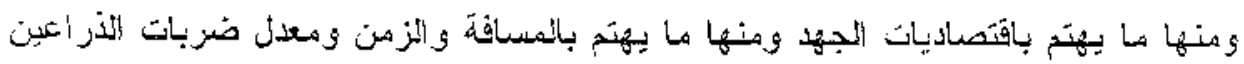

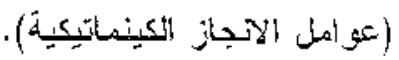


:1) Councilman حيث أنشار كل من أست

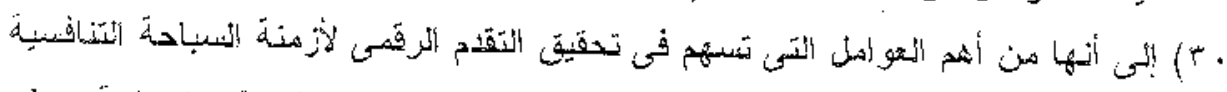

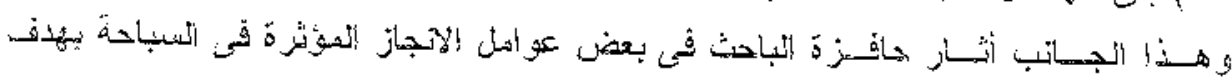

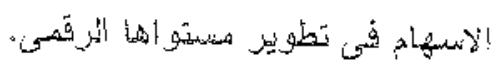

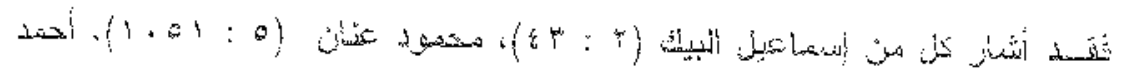

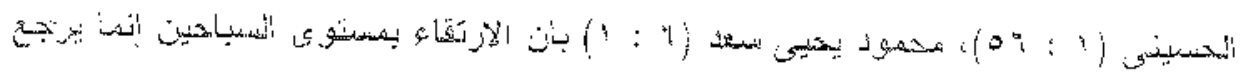

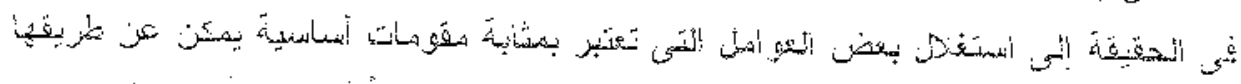

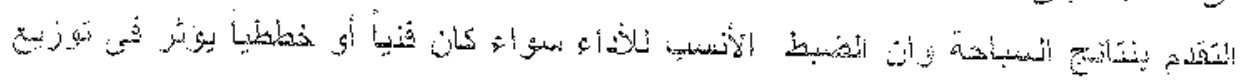

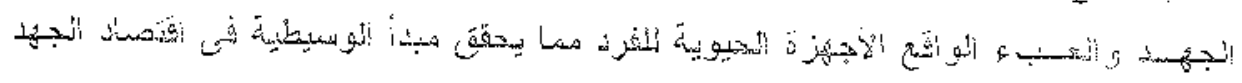

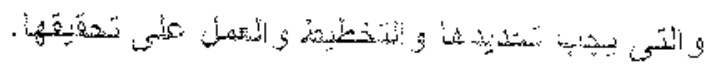

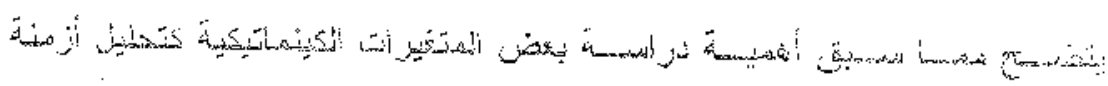

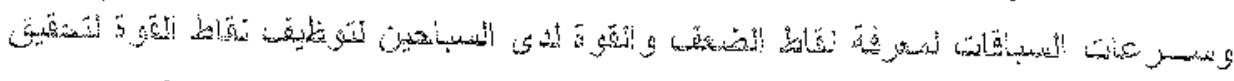

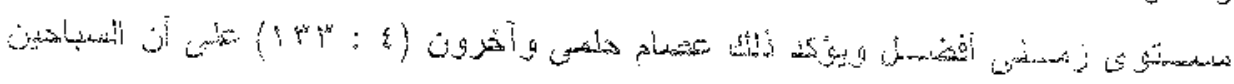

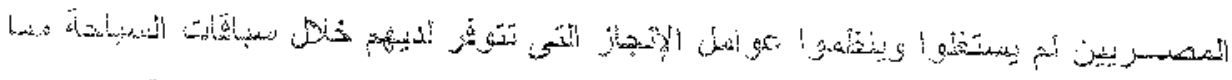

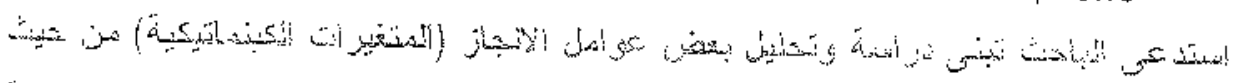

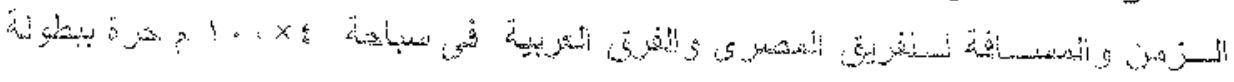

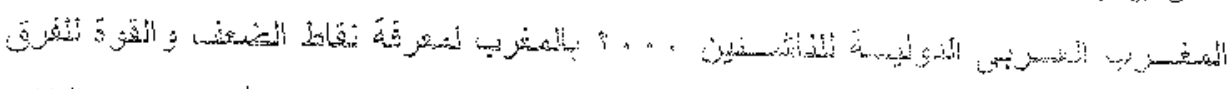

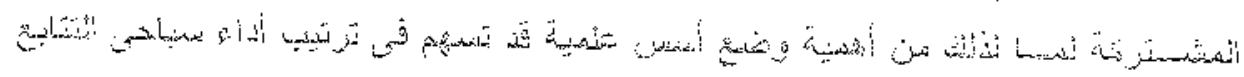
.

Rosermolimportances : : 


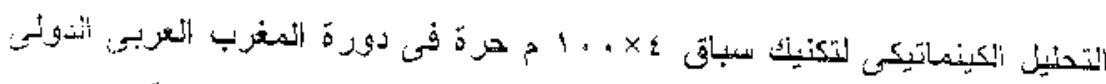

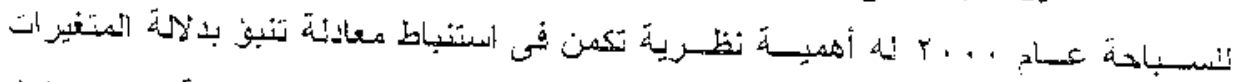

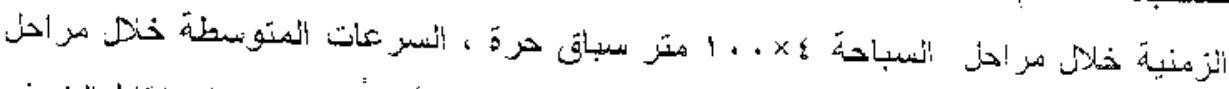

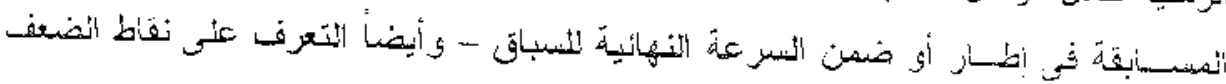

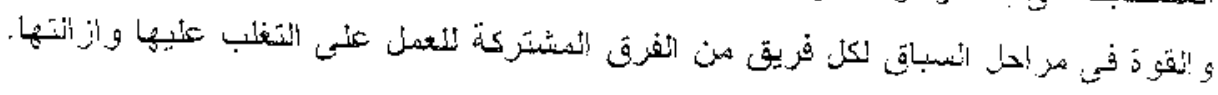

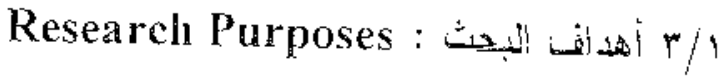

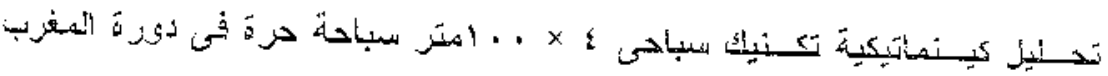

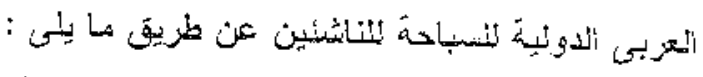

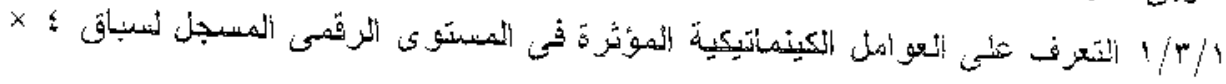

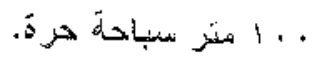

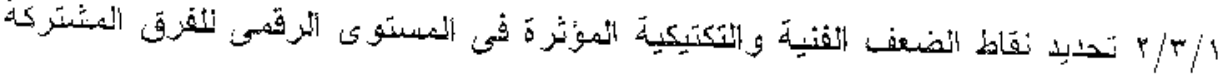

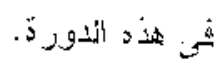

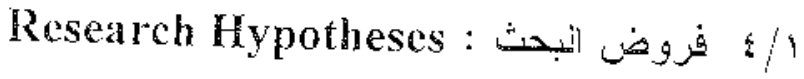

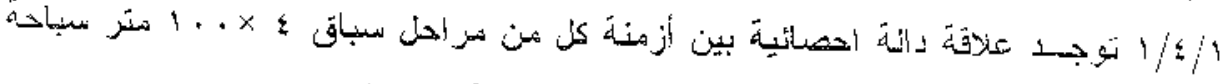

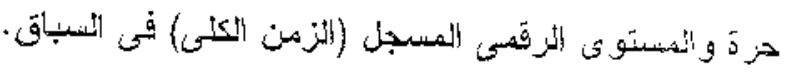

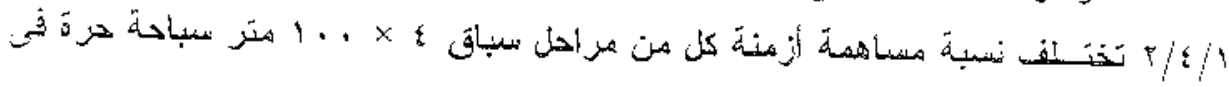

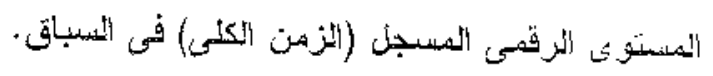

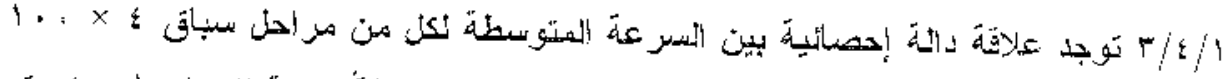

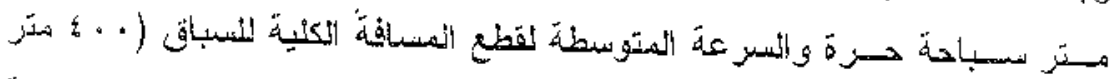

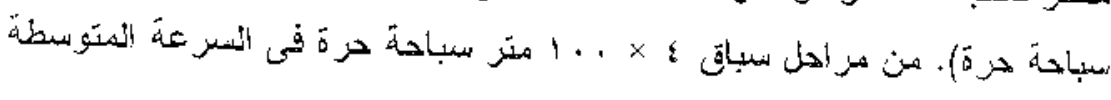

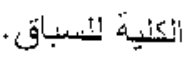

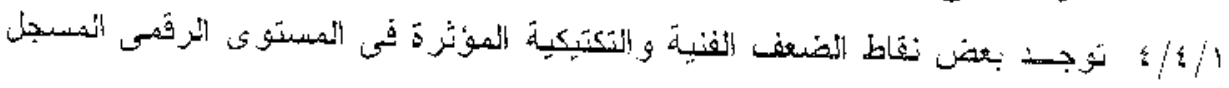

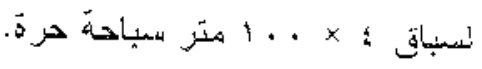




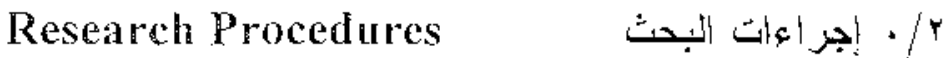

Research Method 1/r

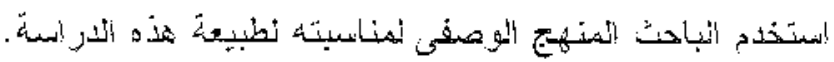

Research Subjects عبنة النجث

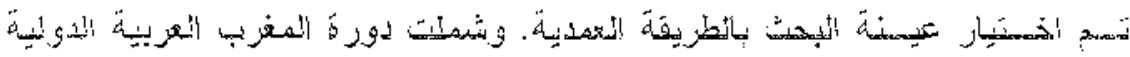

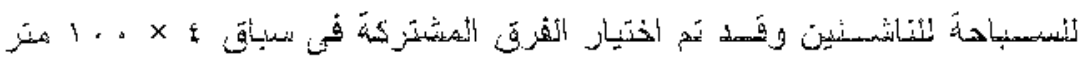

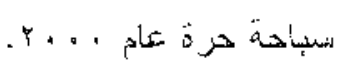

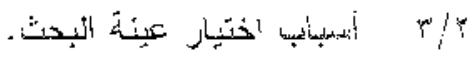

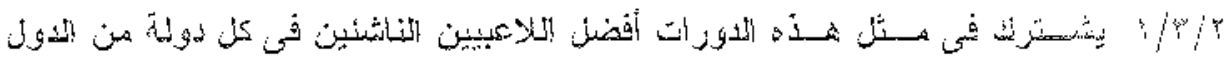

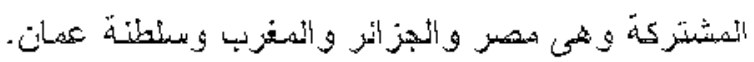

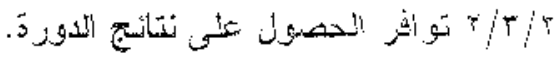

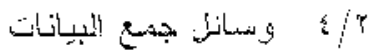

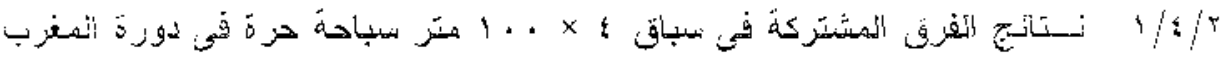

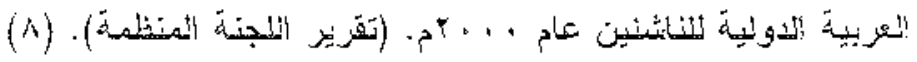
$r / \% / \%$ Temporal Analysis

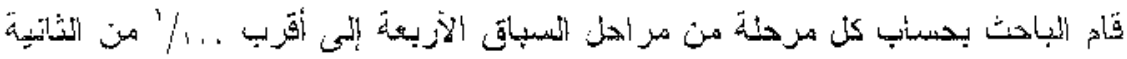

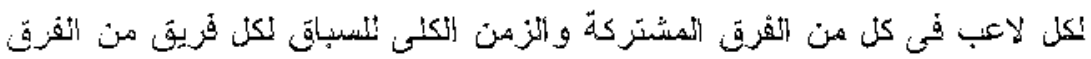

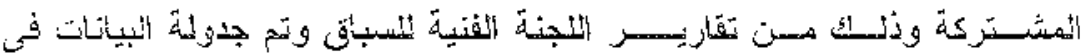

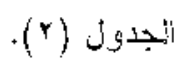

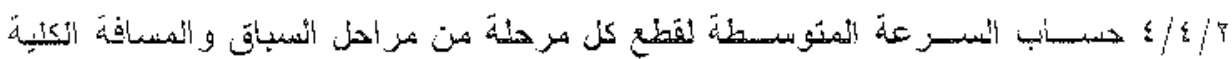

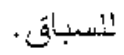




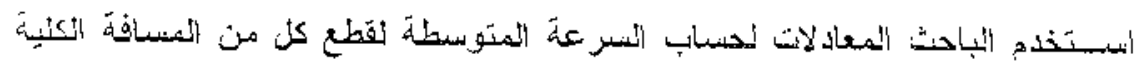

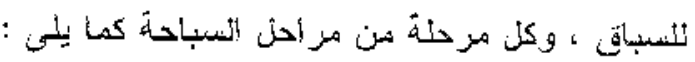

$$
\begin{aligned}
& v=\frac{D}{t}
\end{aligned}
$$

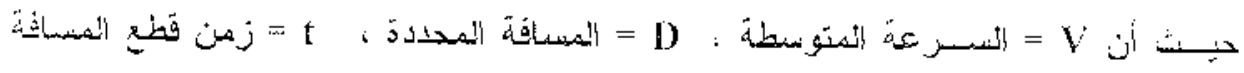

انهحدة (1)

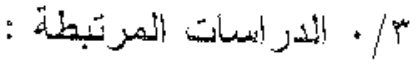

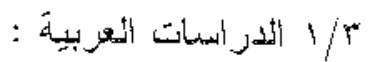

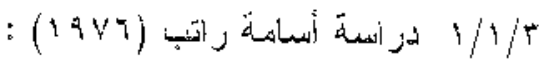

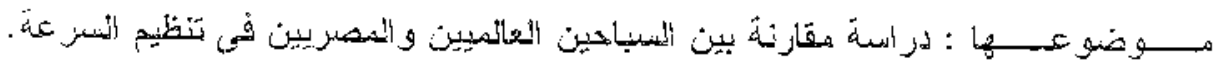

$$
\text { : }
$$

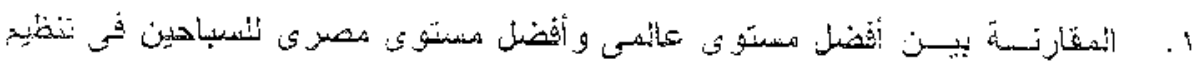

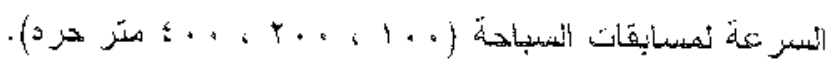

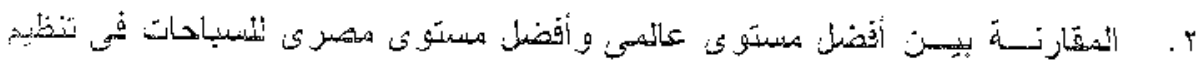

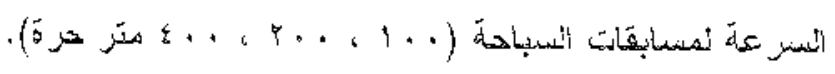

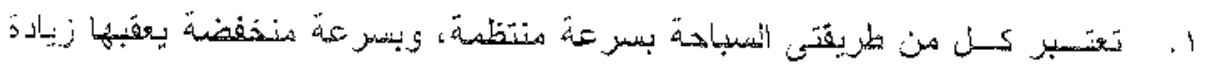

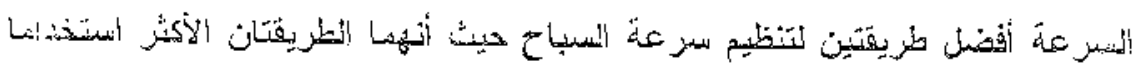

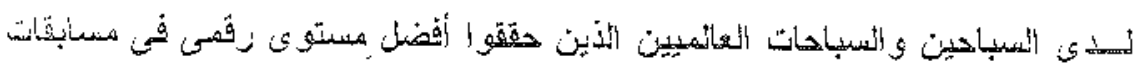

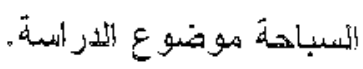

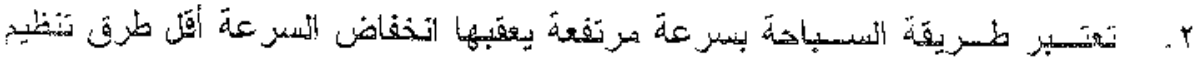

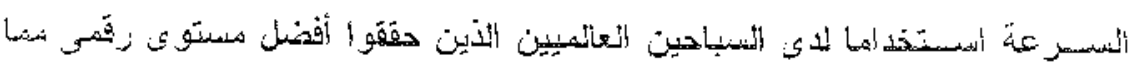

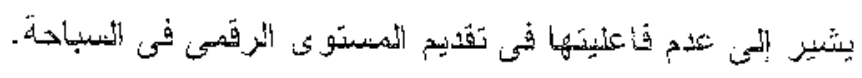

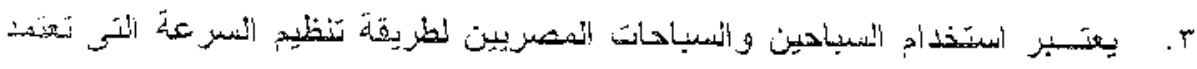

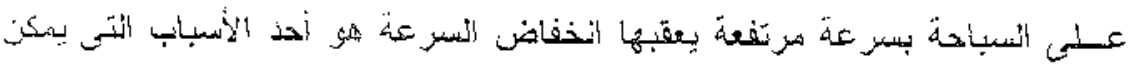




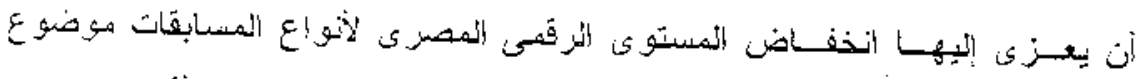

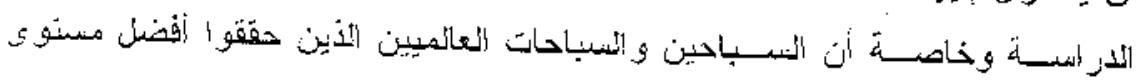

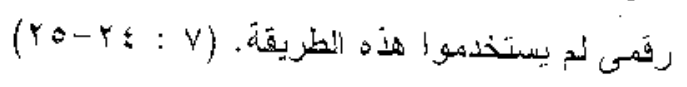

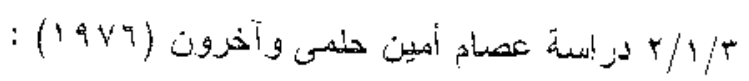

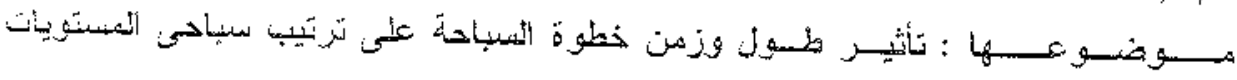

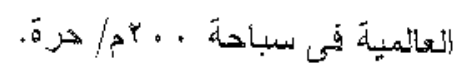

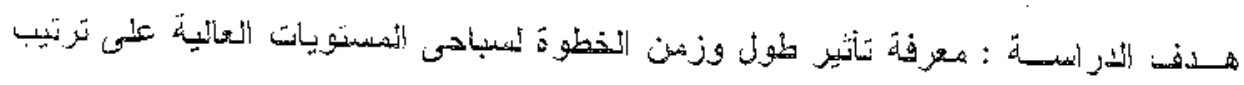

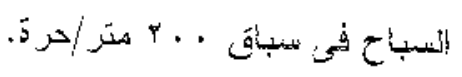

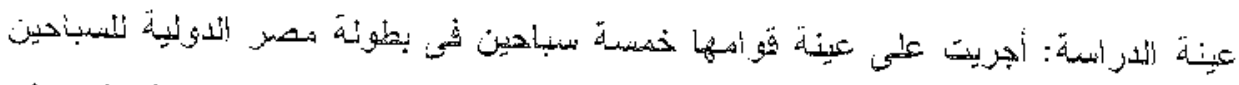

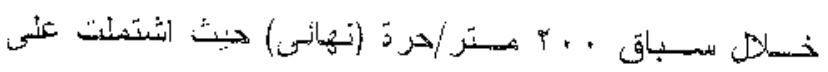

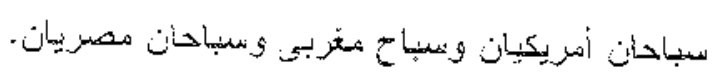

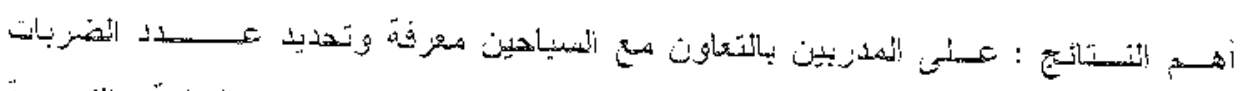

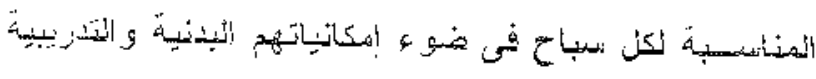

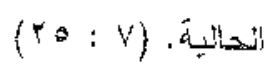

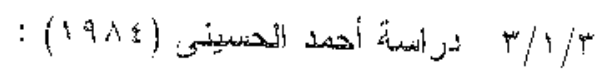

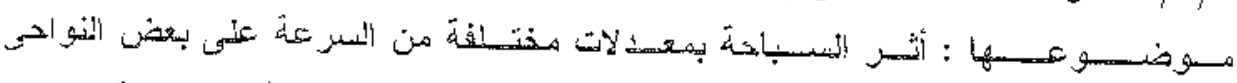

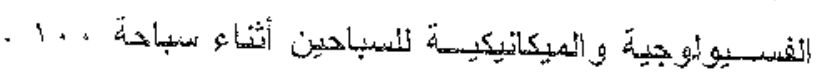

$$
\text { ( ب... }
$$

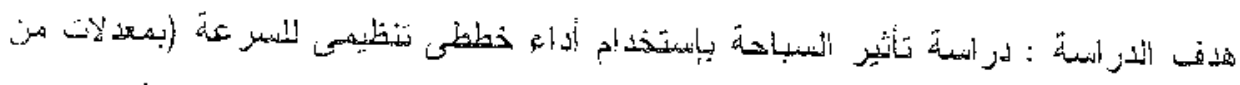

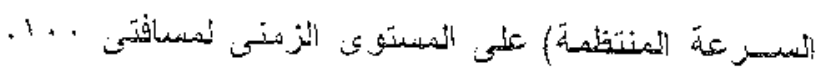

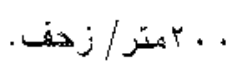

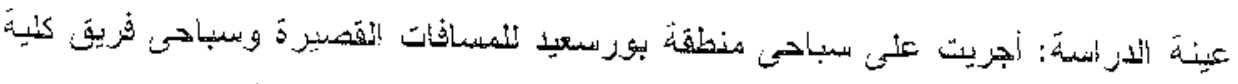

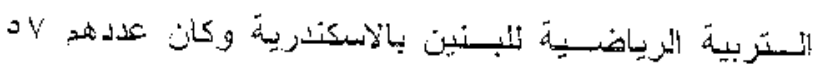

$$
\text { سبأحا. }
$$




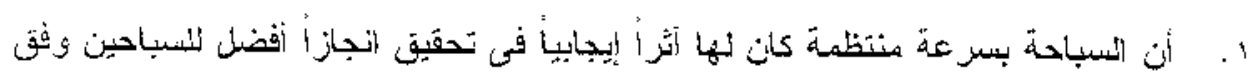

$$
\text { القعز اتص الفزدينة. }
$$

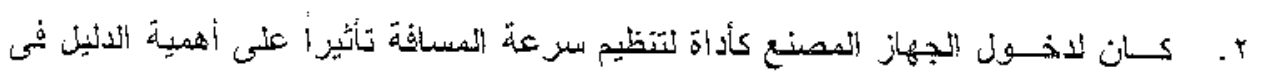

$$
\text { تحسين الإحجاز الخاص بالنسباحين. }
$$

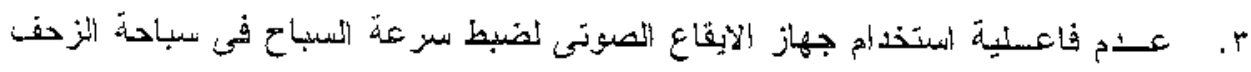

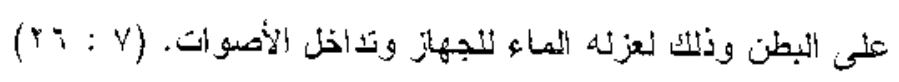

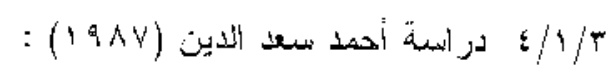

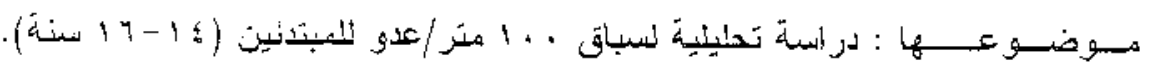

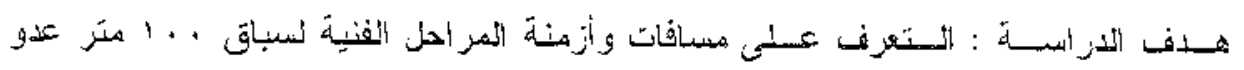

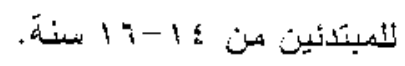

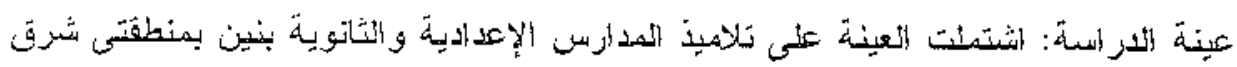

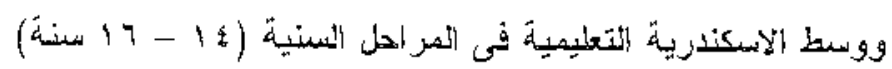

أهم المنتائج :

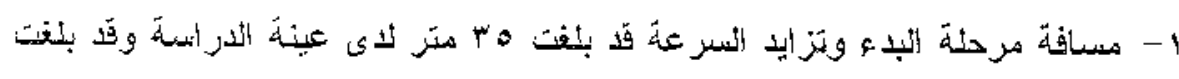

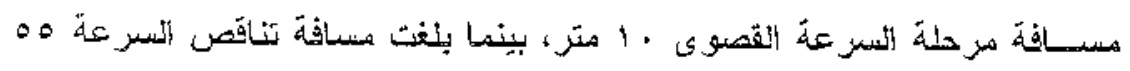
منز

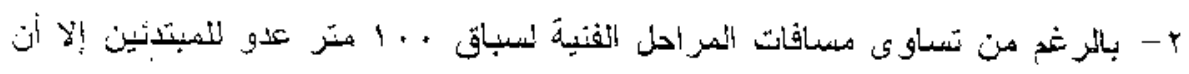

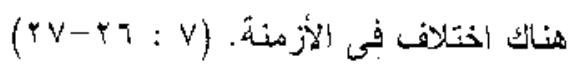

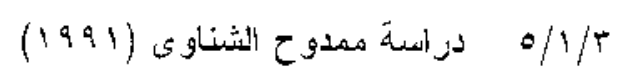

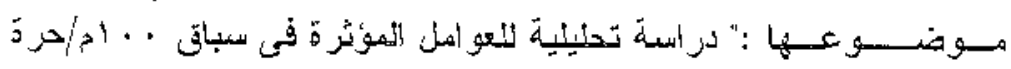

$$
\text { : }
$$

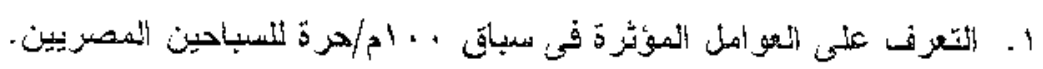

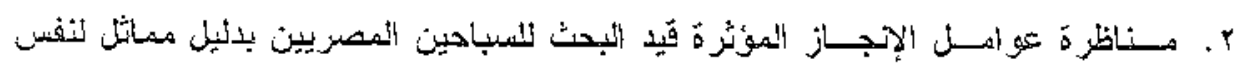

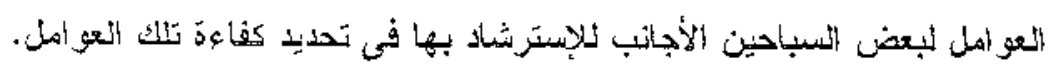


عينة البحث : تم اختيّر العينة بالطريقة التعمدية من مجتمع السباحين المصريين المماربسين

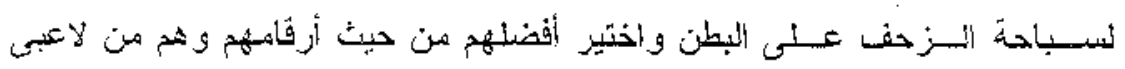

$$
\text { المفريق القومى المصر ع وكان عددهم سنت سباحين. }
$$

أهمج النتانج : بان

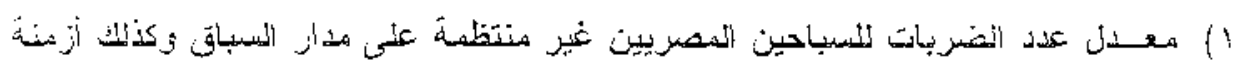

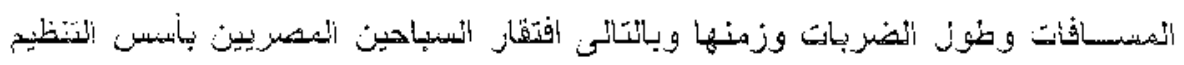

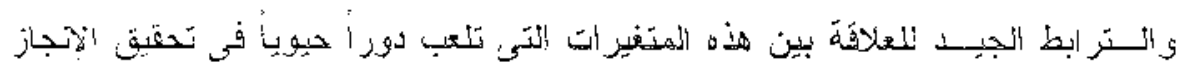

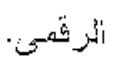

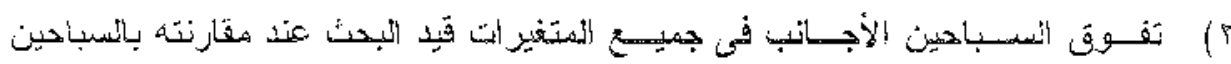

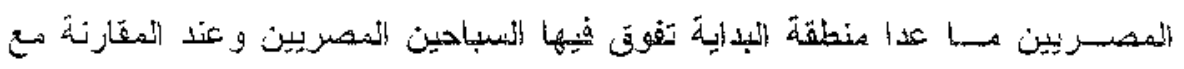

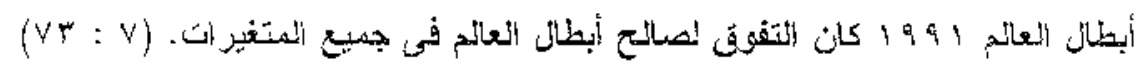

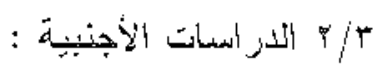

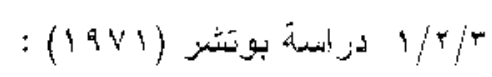

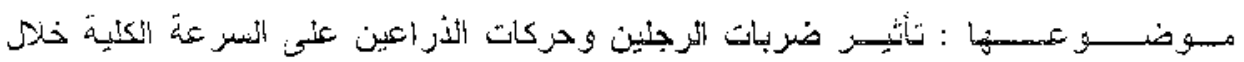

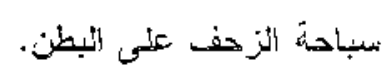

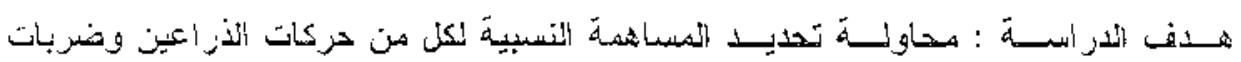

$$
\text { • الزرجنين. }
$$

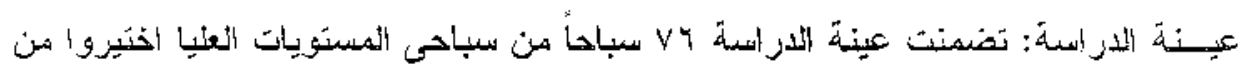

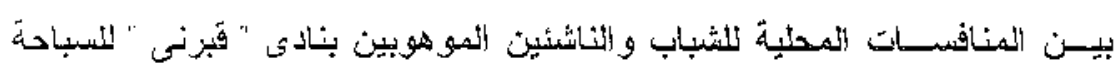

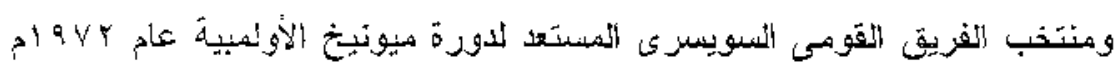

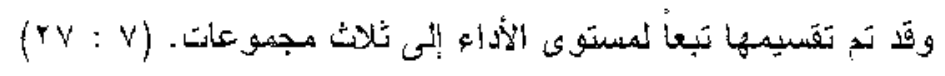

$$
\text { r/r التعليق على الدزاسات المرتبطة }
$$

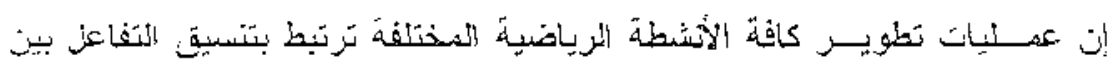

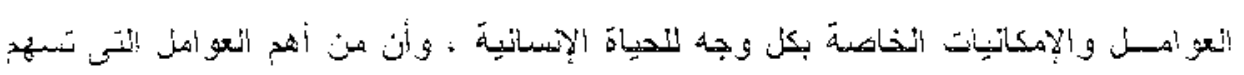

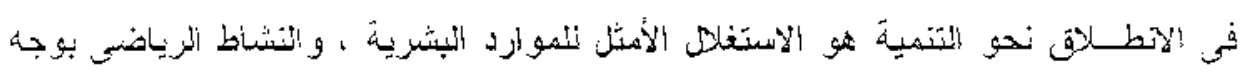




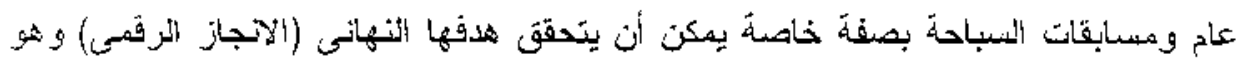

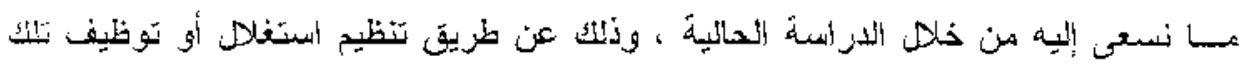

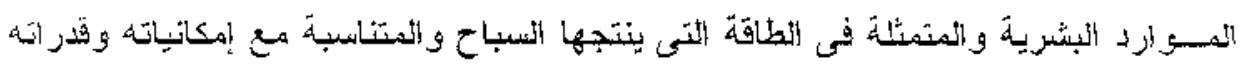

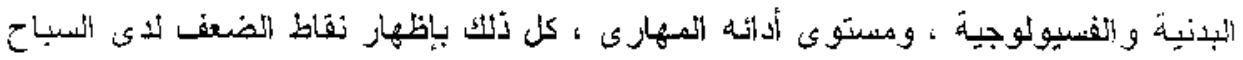

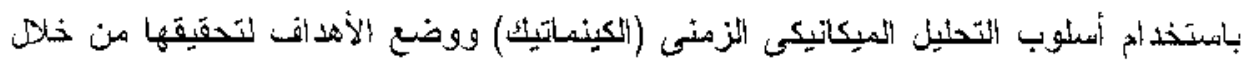

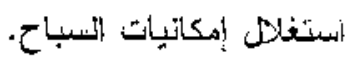

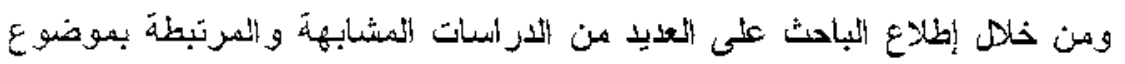

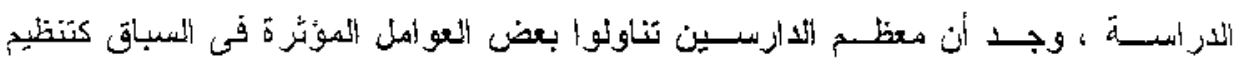

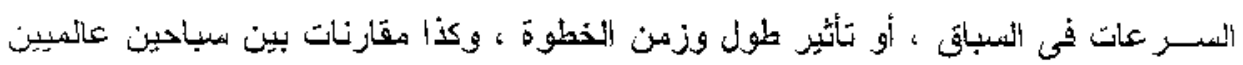

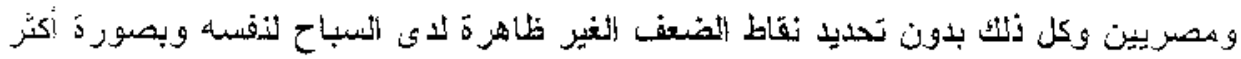

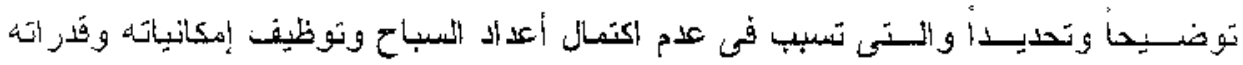

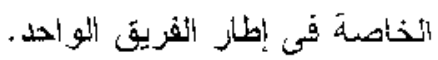

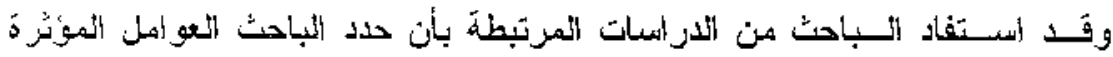

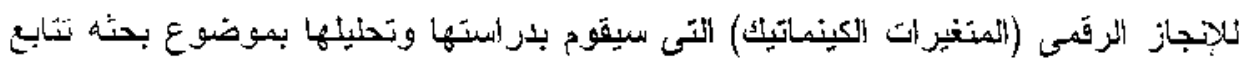

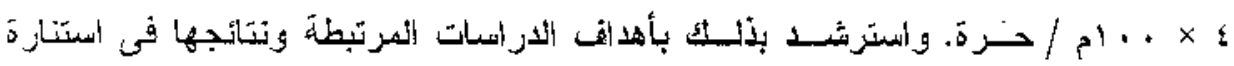

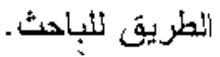

وتم جدونة البيانات فى الجدول (r)

$$
\text { الحاسب الآلى ولى }
$$

المتخدم الباحث في المعالجات الاحصائية الثبرنامج الاحضائى statistics systat

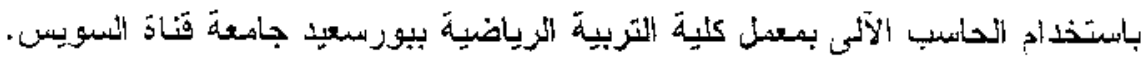


جلول (1)

خصانص عينة البحث في سباق ع × . . ام حرة

\begin{tabular}{|c|c|c|}
\hline المسنتوى المسنى & النمستوى التزقىى (ث) & انجنسية \\
\hline \multirow{5}{*}{$\begin{array}{l}2 \\
2 \\
0 \\
1 \\
0 \\
0 \\
0 \\
0\end{array}$} & YYY, Q1 & الجز ائز \\
\hline & rYV, rt & مصــر \\
\hline & $r r r, 11$ & سوريا \\
\hline & $Y M Y, Y \varepsilon$ & المغزب \\
\hline & $r \leqslant 1, \ldots$ & سلطة غمنان \\
\hline
\end{tabular}


USTATUS JOB = ON

SIRTLS PAGE = OFF

STA $2 U S$ DEVICE $=$ ON

STATUS TIMED $=0$ 
3
4
3
3
3

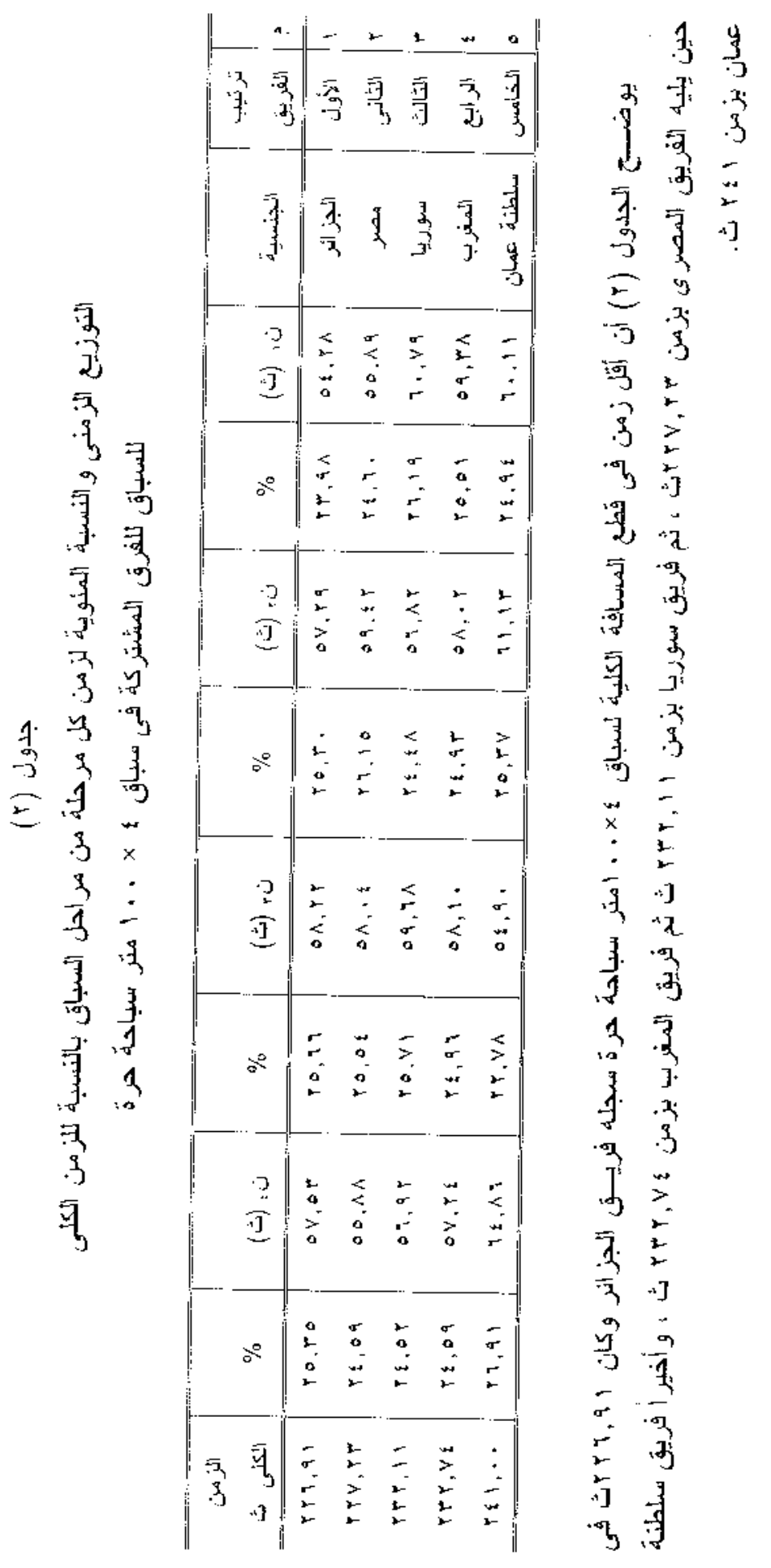




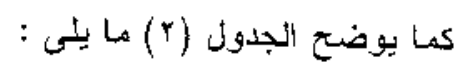

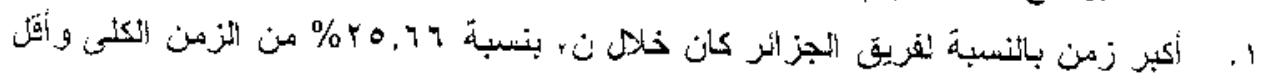

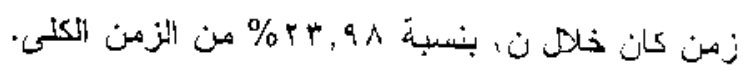

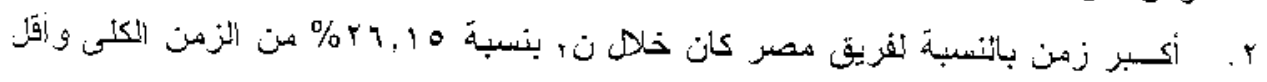

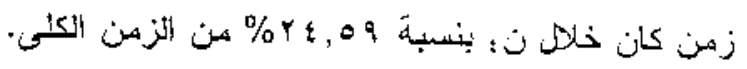

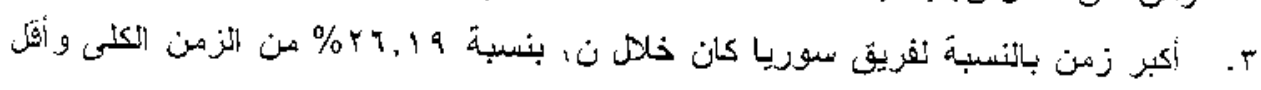

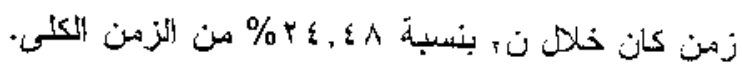

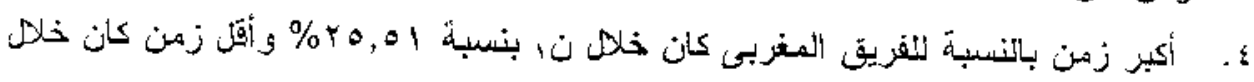

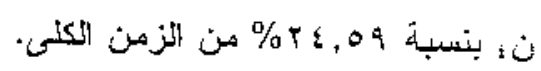

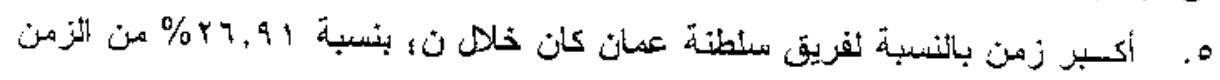

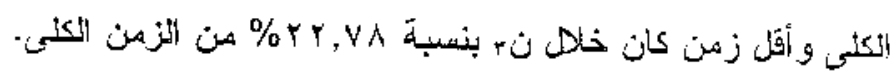

$$
\text { جنون (r) }
$$

\begin{tabular}{|c|c|c|c|c|c|c|c|}
\hline $\begin{array}{c}t \\
(3 / 3)\end{array}$ & $\begin{array}{c}1 \\
(4 / 2)\end{array}$ & $\begin{array}{c}r_{r} \\
(ث / \theta) \\
\end{array}$ & $\begin{array}{c}r_{1} \\
(3 / \mathrm{e})\end{array}$ & $\begin{array}{l}v_{1} \\
(4 / 2)\end{array}$ & الجنسية & استح الفزيقّة & P \\
\hline 1,184 & $1, v r$ & $1, k 1$ & $1, v \varepsilon$ & $1, A \varepsilon$ & الجز ائزر & الفريق الأول & 1 \\
\hline $1, v i$ & $1, \mathrm{VA}$ & $1, v r$ & 1,71 & $1, \mathrm{VA}$ & مصر & اتفريق الثنانيى & $r$ \\
\hline $1, \mathrm{Vr}$ & $1, v 0$ & $1,4 \mathrm{~V}$ & $1, v 0$ & $1, Y \leqslant$ & سوريا & الفريق الثادث & $r$ \\
\hline $1, v_{1}$ & $1, v \varepsilon$ & $1, Y Y$ & $1, \mathrm{Vr}$ & 1,91 & كلمغرب & الففزيق الثز ابع & ؛ \\
\hline 1, is & $1,0 \leqslant$ & $1, A T$ & $1,7 \pi$ & 1.87 & سلطنة عمان & الفريق أخامس & 0 \\
\hline
\end{tabular}

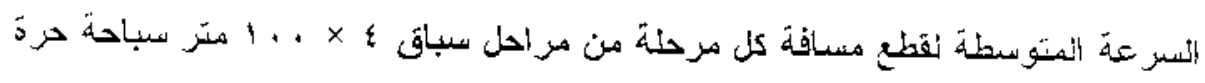

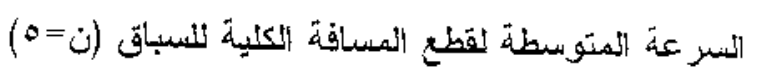

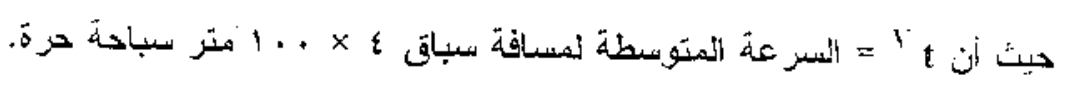

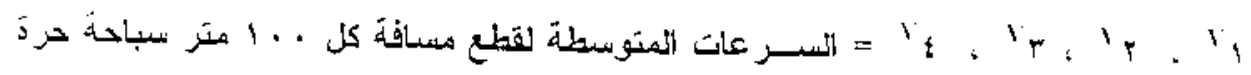

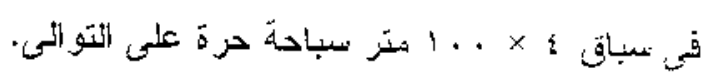




\section{(4) (2) (2)}

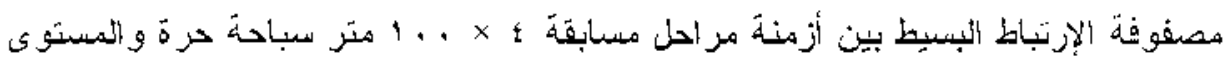

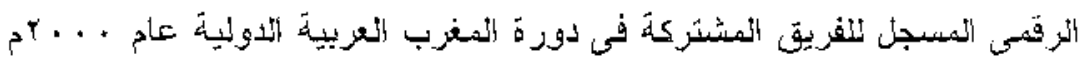
$(0=\dot{0})$

\begin{tabular}{|c|c|c|c|c|c|}
\hline$y$ & ن & ن & نे & ن & الثتغنيز اتت \\
\hline * , AYV & $* .,+49$ &., $117-$ & ,IKA & & $\dot{s}$ \\
\hline${ }^{*}{ }^{*}, \Delta r$. & $*, V \leq$. & $* \cdot 91 \leq-$ & & & ri \\
\hline 非, I Y & $* \cdot 9 \cdot 1-$ & & & & $r$ \\
\hline$* a, A \leq 1$ & & & & & 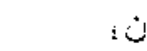 \\
\hline
\end{tabular}

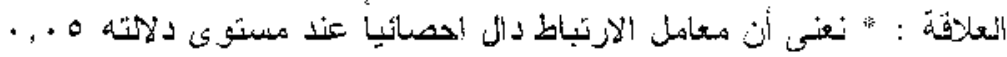

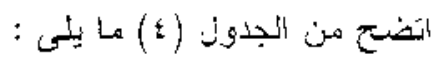

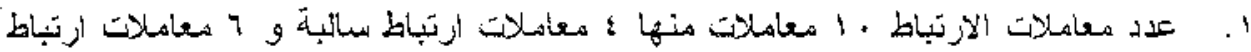

هو جبة.

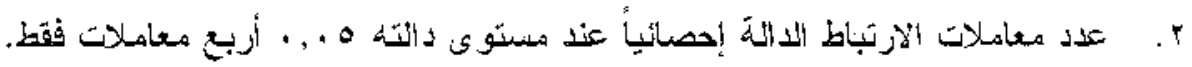

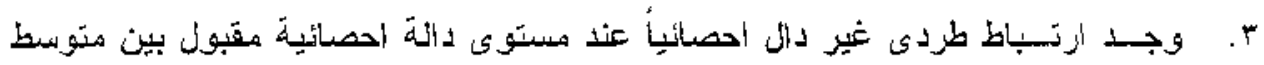

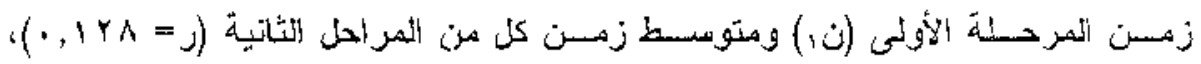

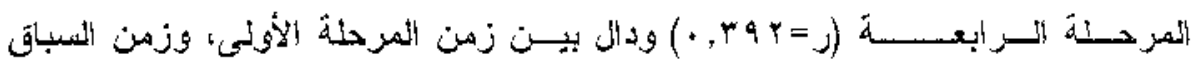

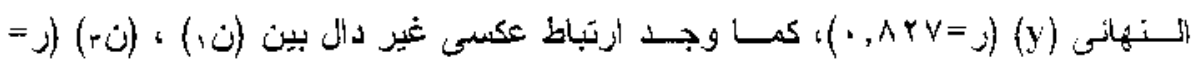
$\cdot(\cdot, 1)$

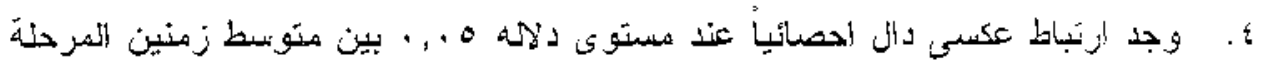

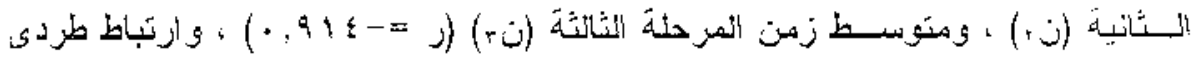

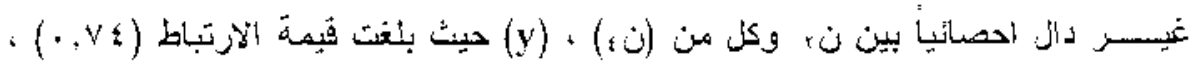

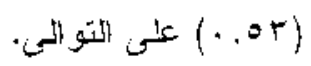

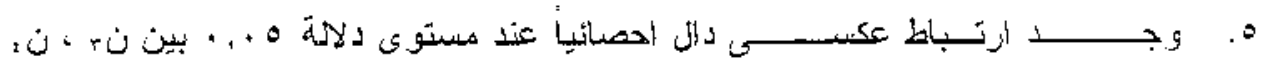

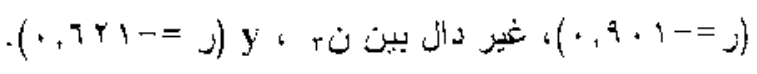




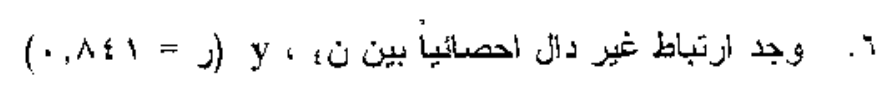

\section{(0) جل}

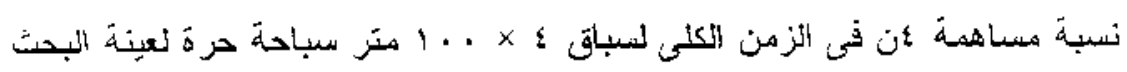

\begin{tabular}{|c|c|c|c|c|c|}
\hline 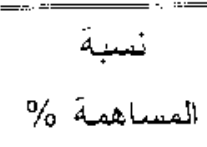 & $\bar{F}$ & $P$ & النخطن| & معامل الانحدار & \\
\hline$v \cdot \Lambda$ & $V$, Y VA & $\neg, \vee v \varepsilon$ & $\cdot, \leq \leqslant 9$ & $1, r \leq 5$ & ن؛ \\
\hline
\end{tabular}

يعسرض جـول (0) نسبة مساهمة متوسط زمن قطع المرحلة الترابعة من سباتي ؛

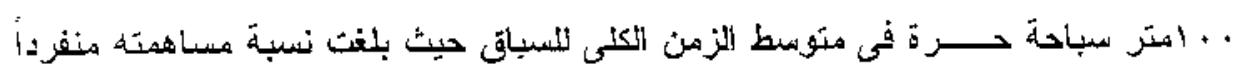

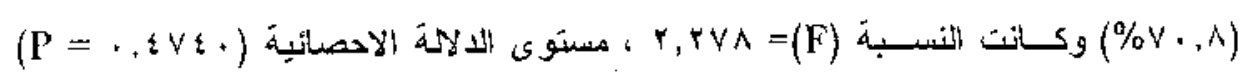

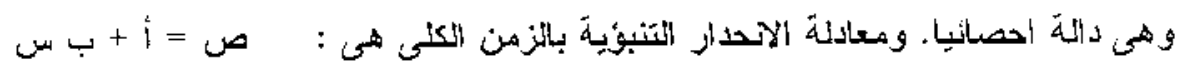

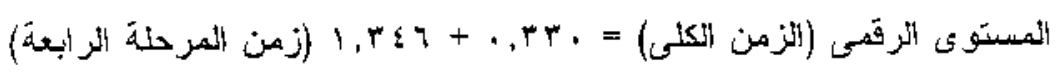


(1) جلول

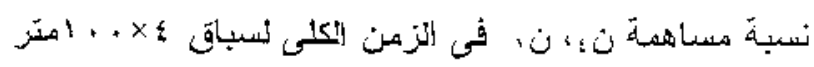

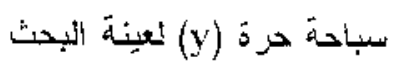

$(v=\dot{0})$

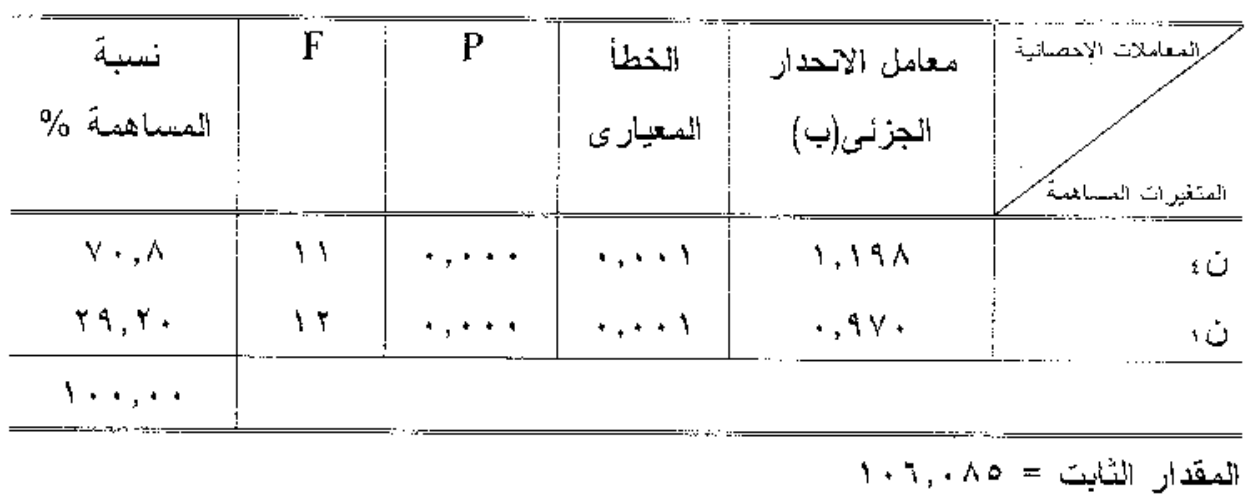

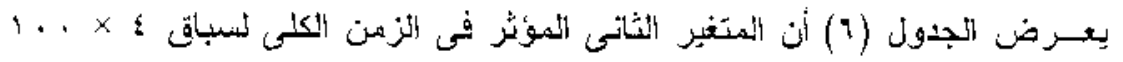

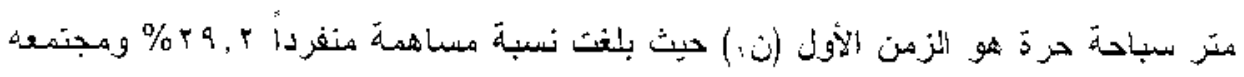

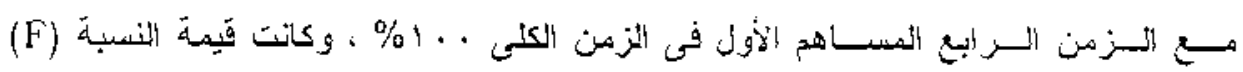

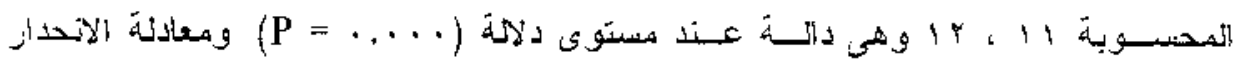

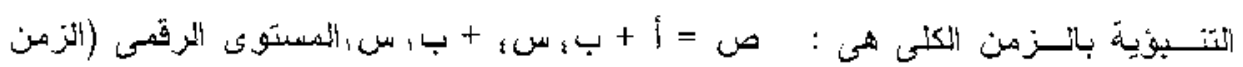

$$
\text { (ن) }
$$




\section{(v) جدول}

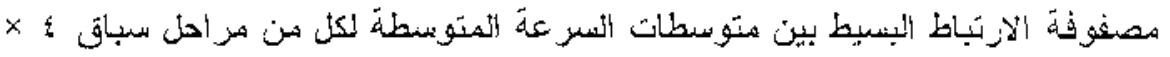

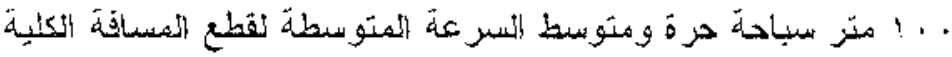

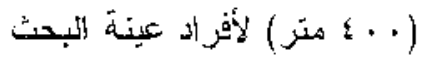

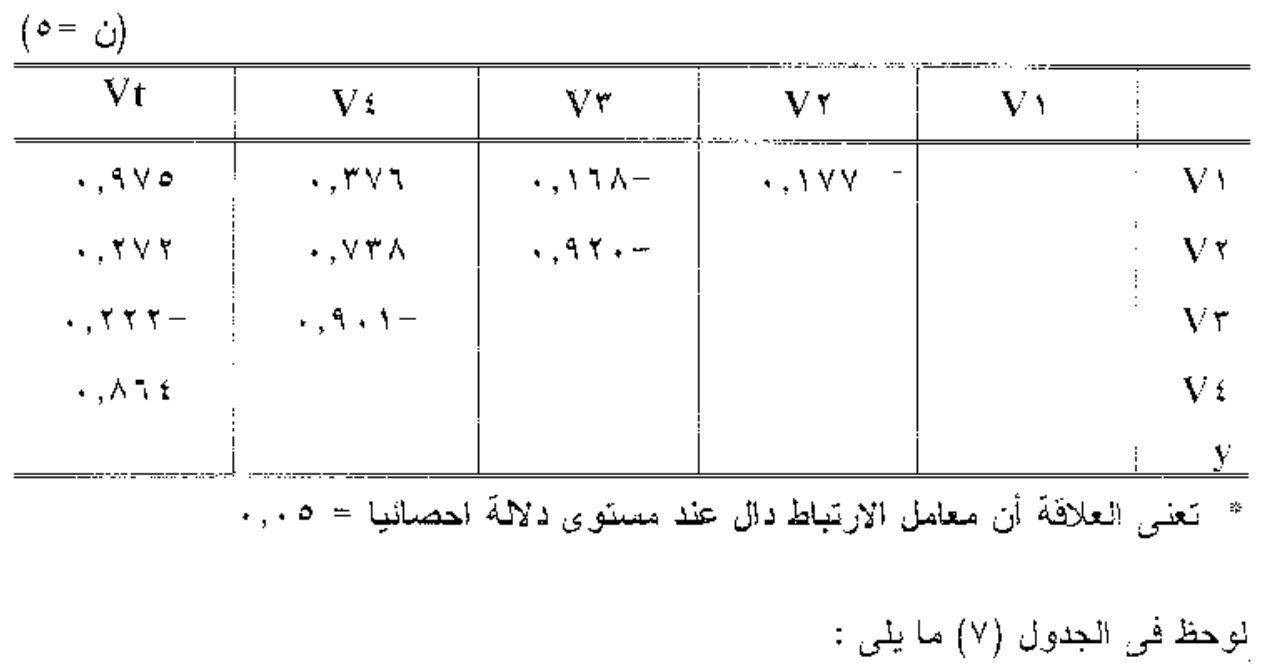

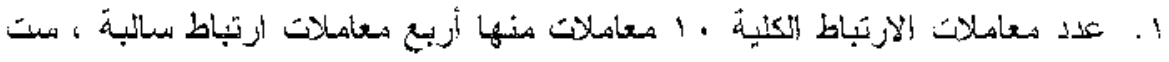

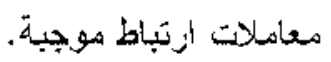

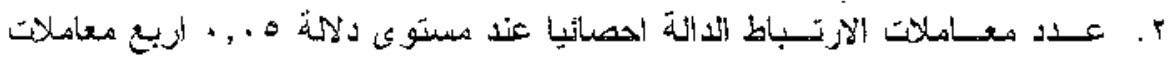

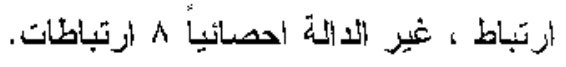

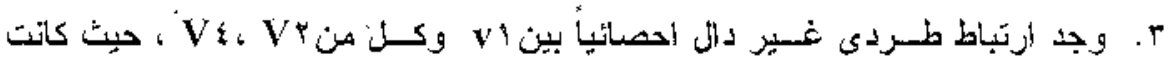

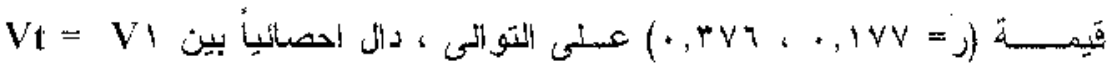

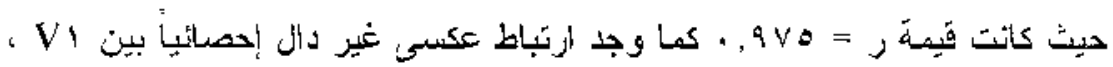

$$
\text { حيث كاتت فيمة (j = }
$$

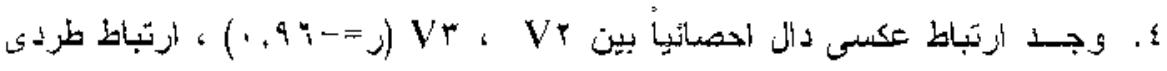

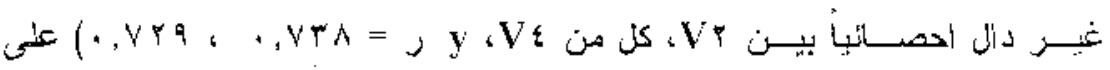

$$
\text { التكو أمى }
$$

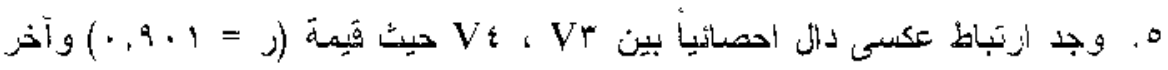

$$
\begin{aligned}
& \text { عكسى عير دال بين }
\end{aligned}
$$

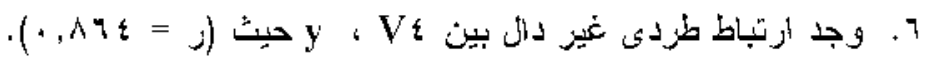




\section{جلدل (A)}

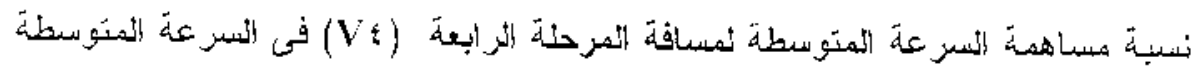

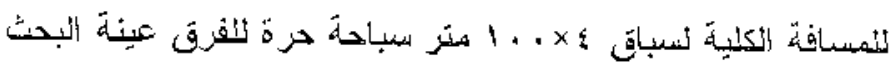

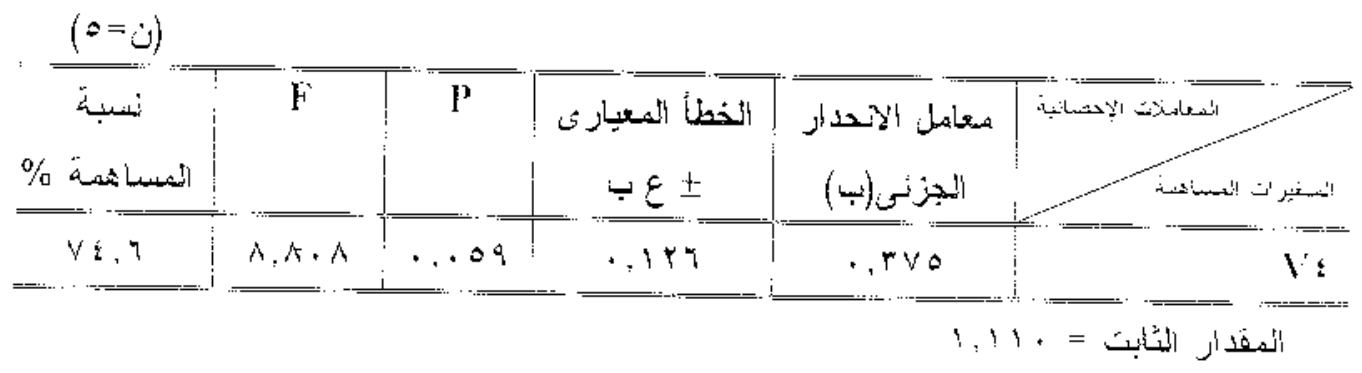

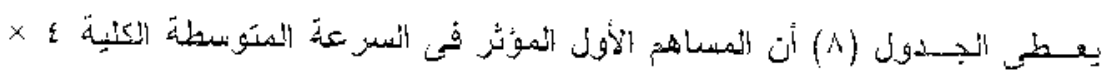

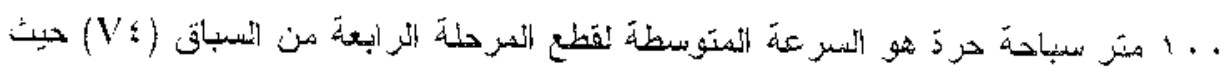

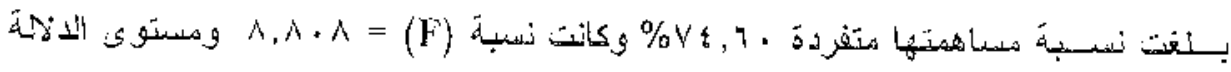

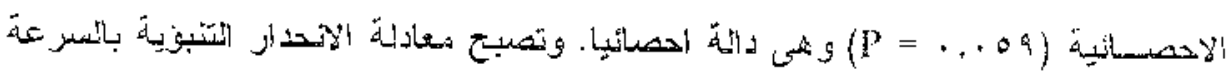

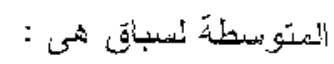

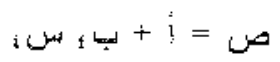

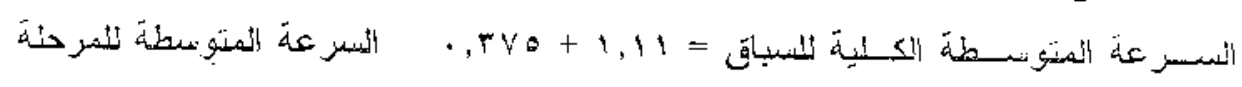

$$
\text { إلز البعة }
$$

\section{جدول (9)}

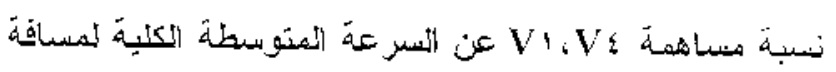

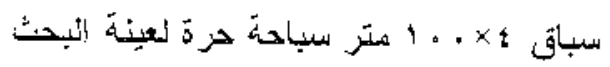

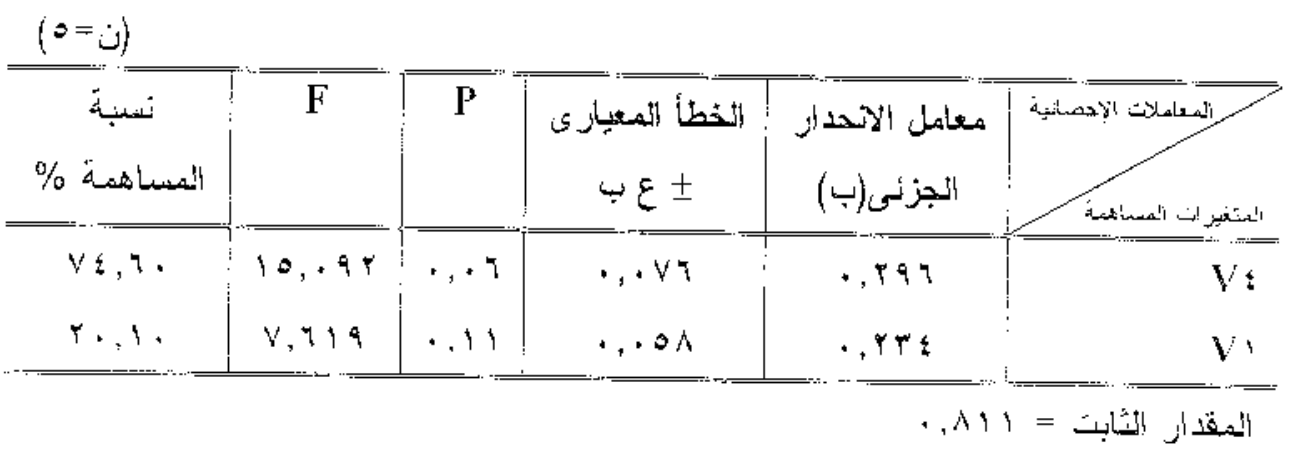




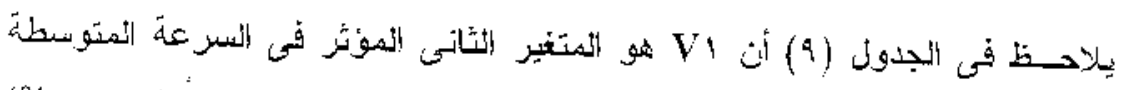

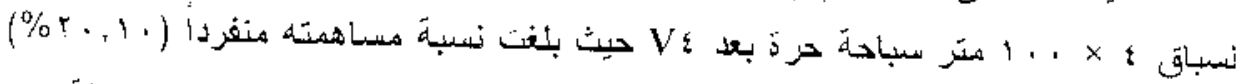

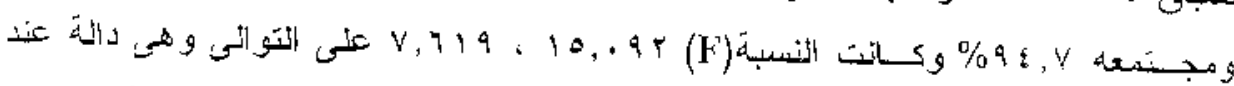

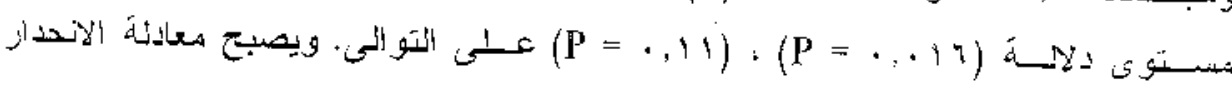

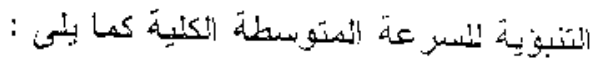
أس

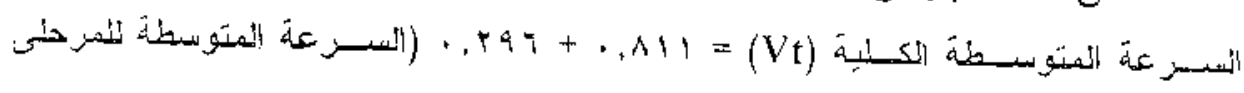

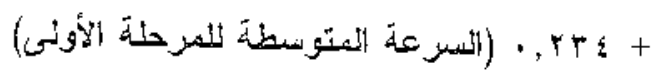

\section{جلون (1.)}

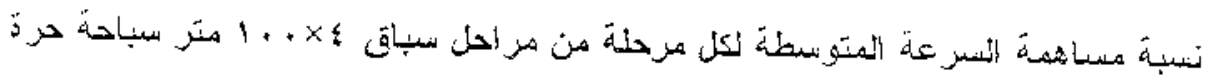

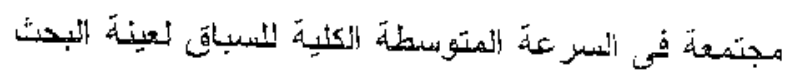
$(s=0)$

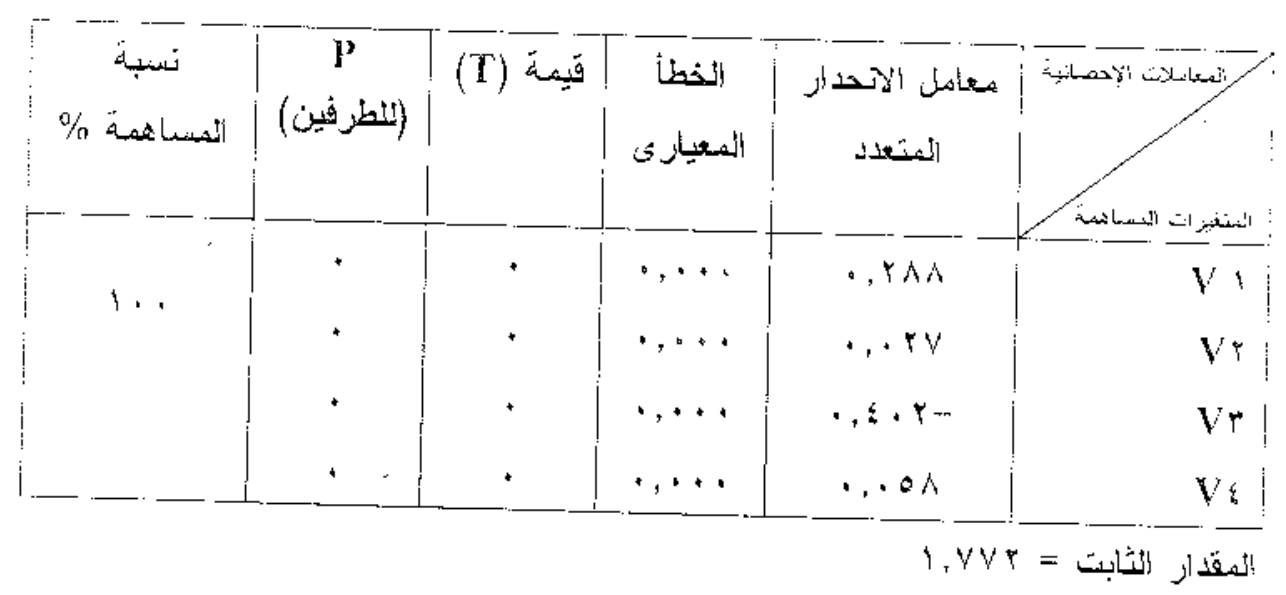

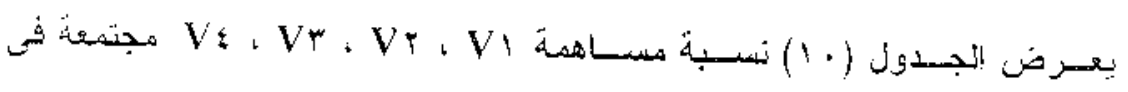

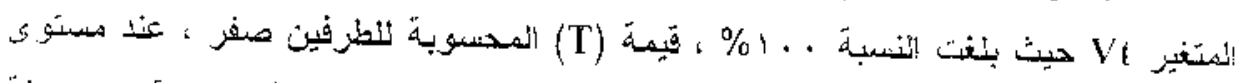

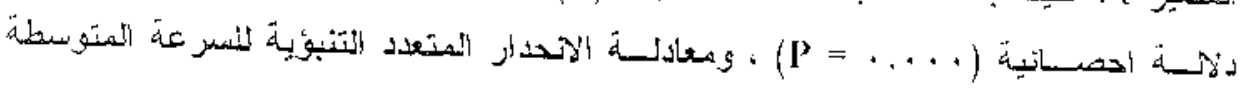

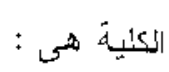




$$
v_{t}=\text { constant }+V_{1} \infty_{1}+V_{2} \infty_{2}+V_{3} \infty_{3}+V_{4} \infty_{4}
$$

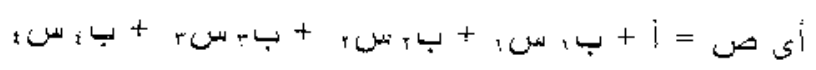

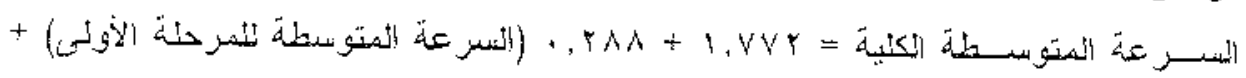

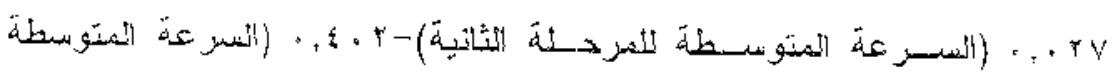

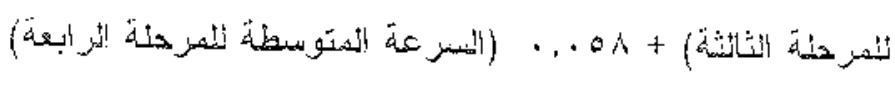

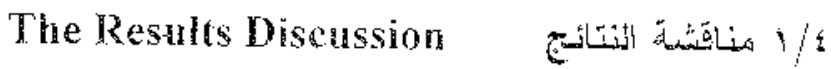

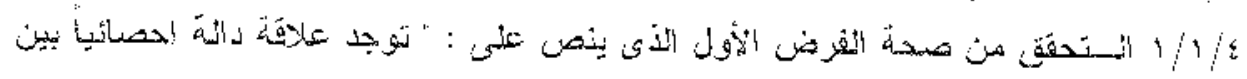

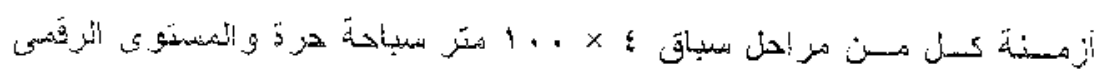

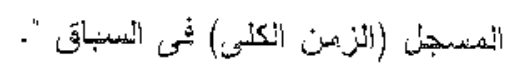

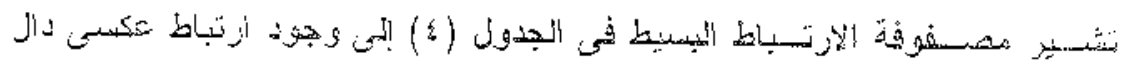

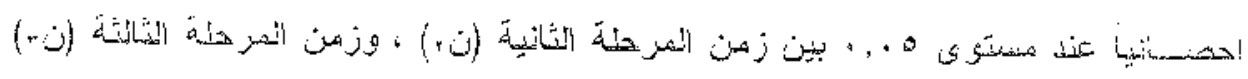

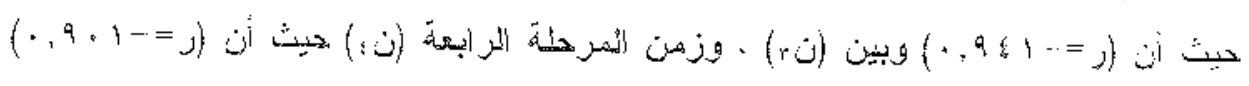

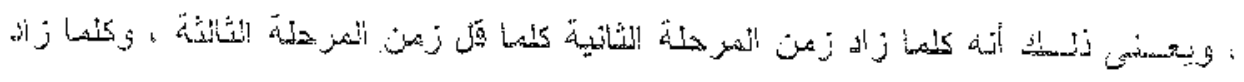

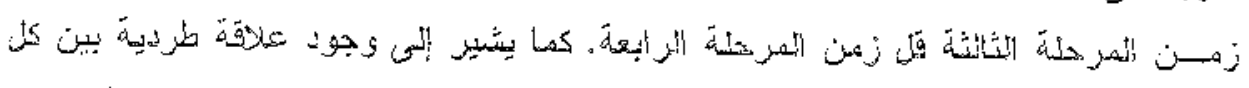

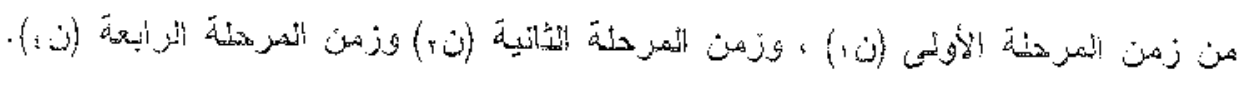

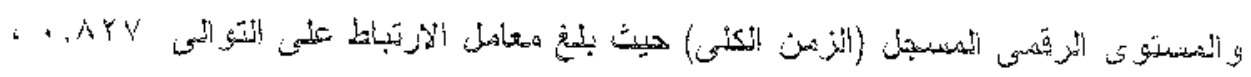

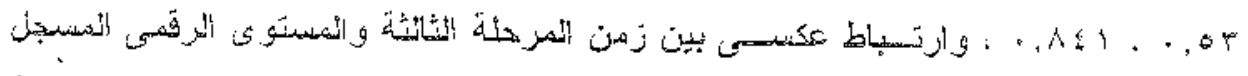

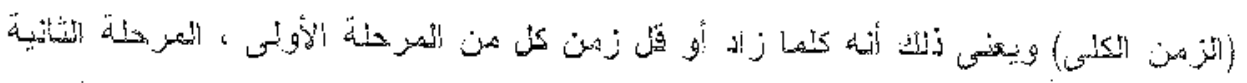

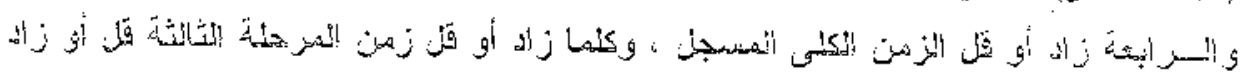

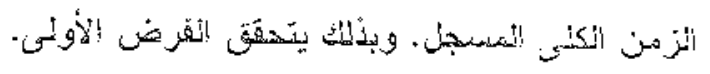

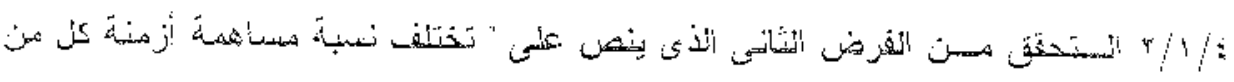

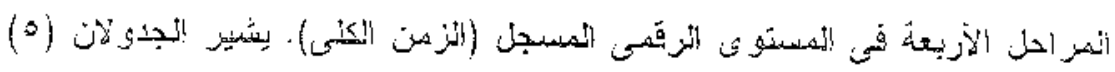

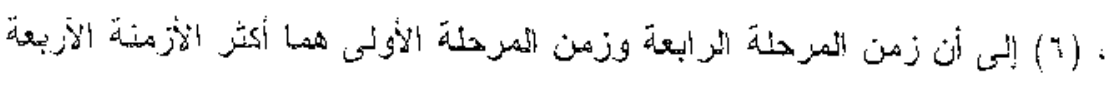

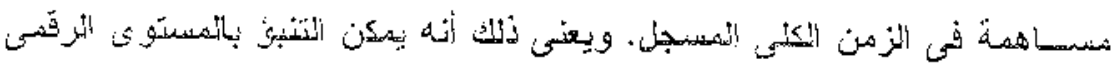


(الـزمن المسجل) عن طريق كل من زمن المرحلة الترابعة وزمن المرحلة الأونى

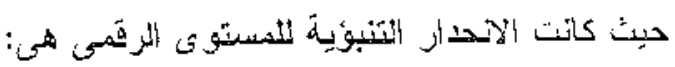

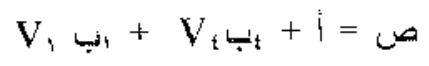

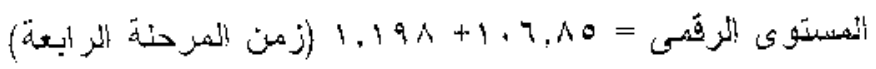

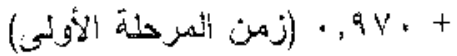

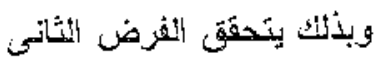

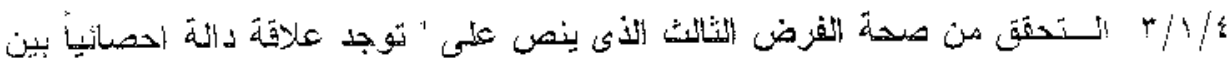

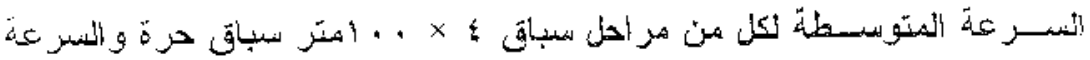

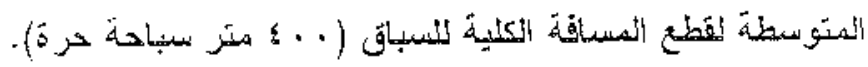

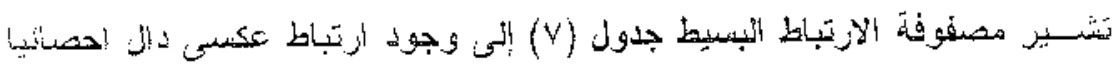

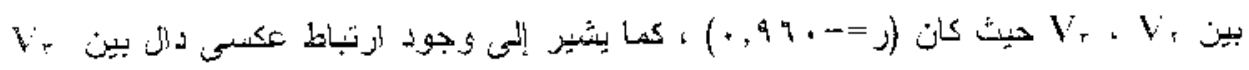

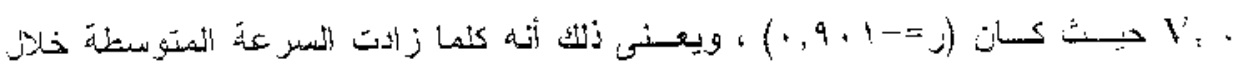

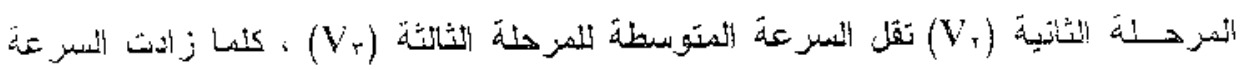

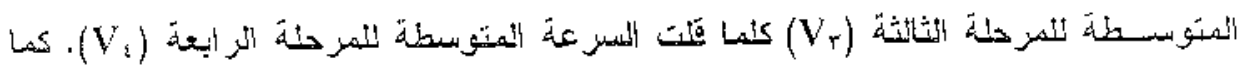

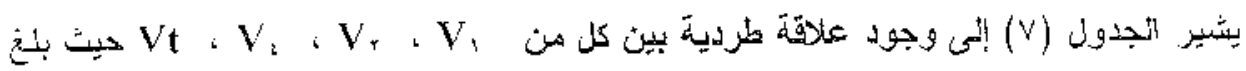

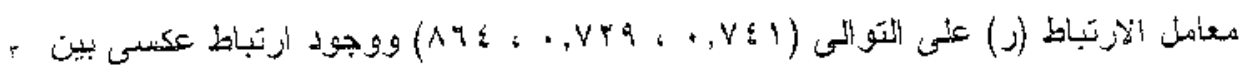

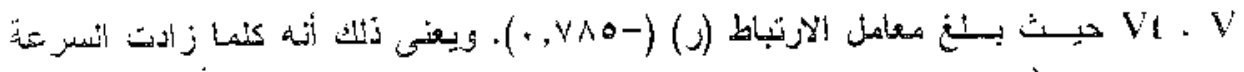

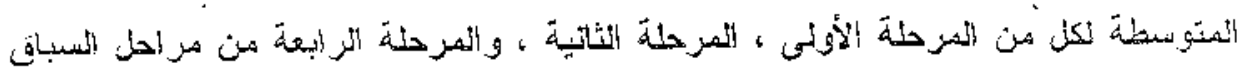

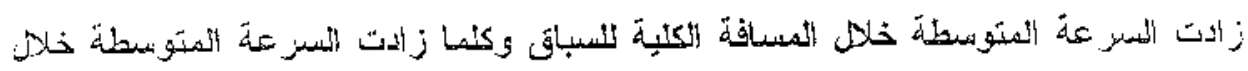

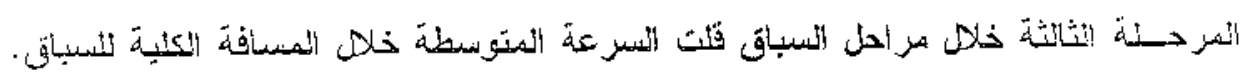

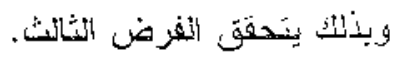

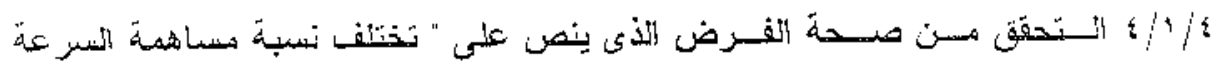

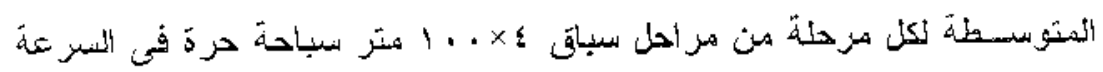

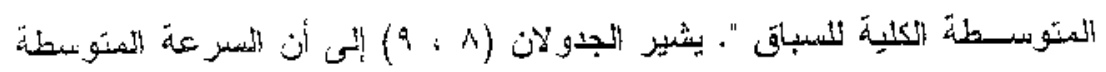

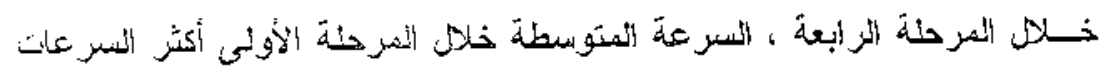

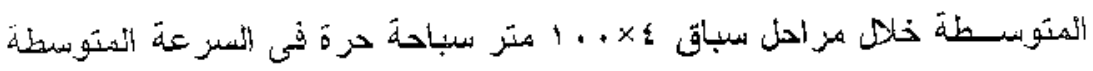




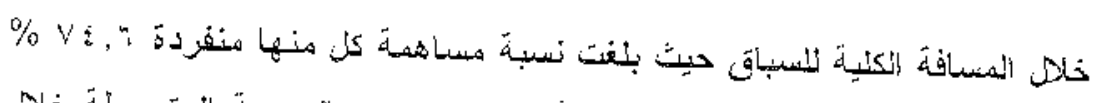

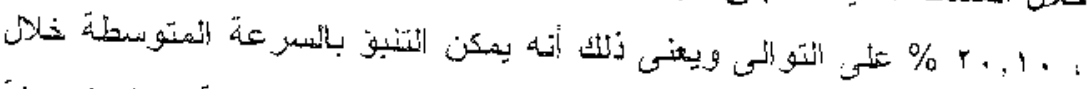

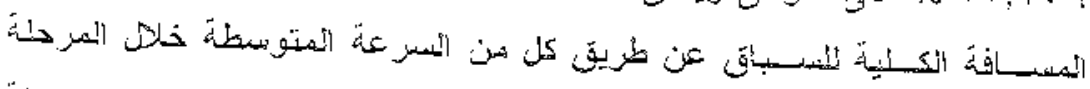

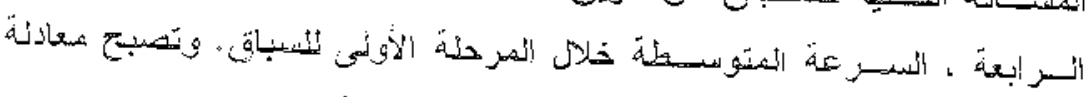

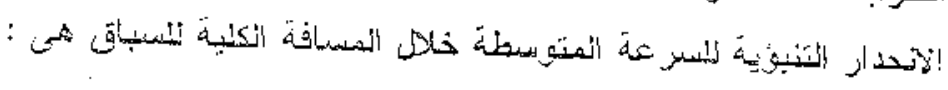

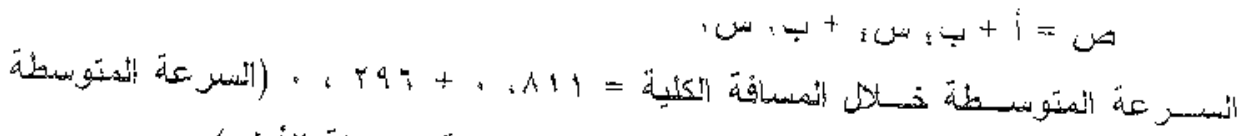

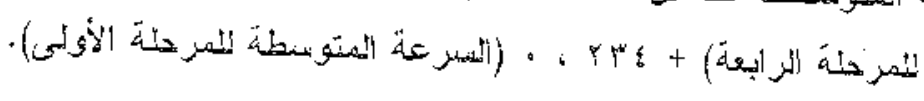

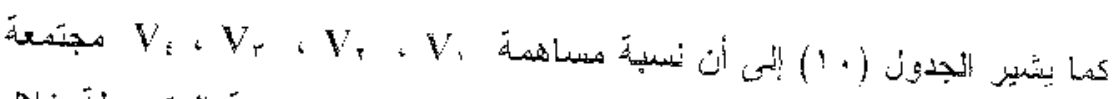

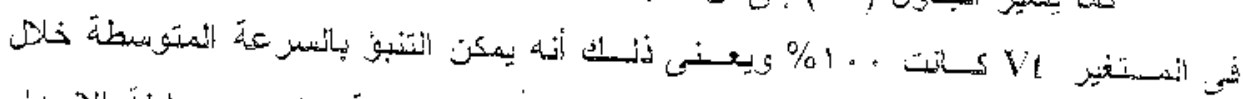

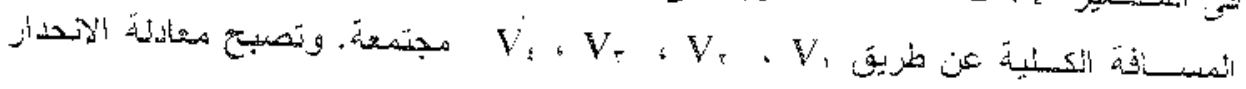

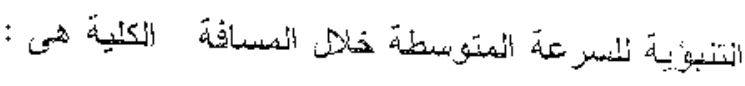

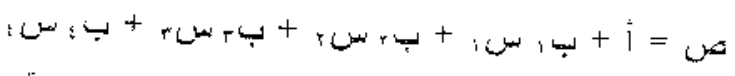

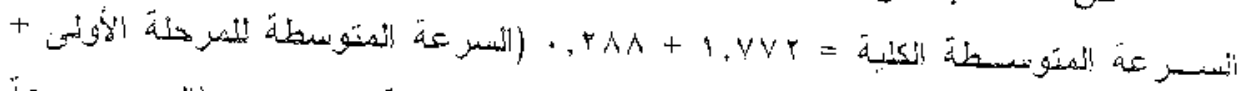

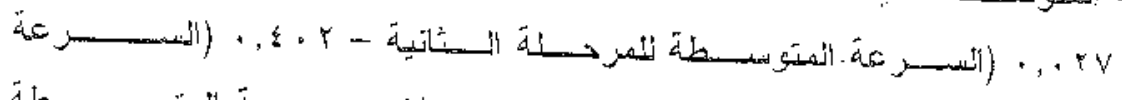

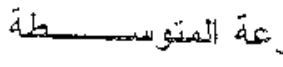

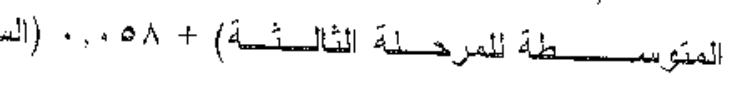

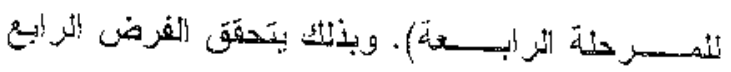

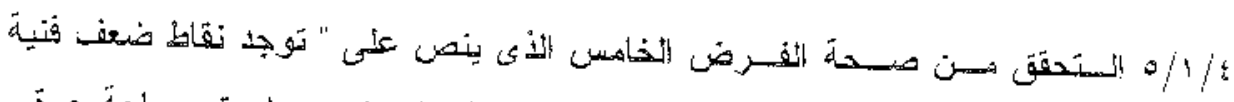

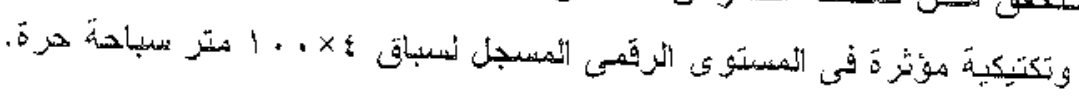

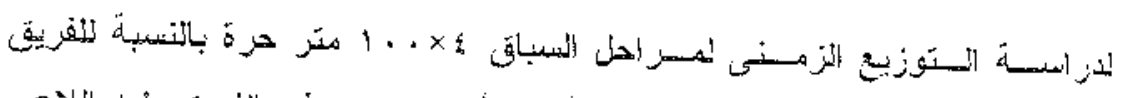

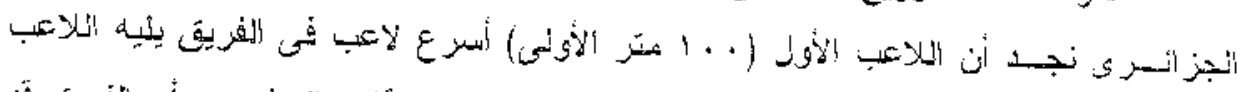

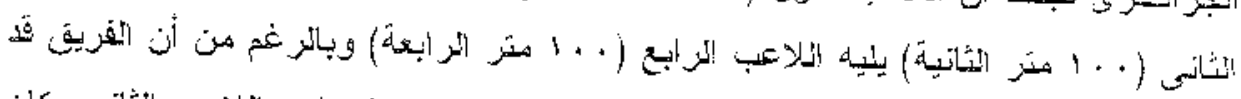

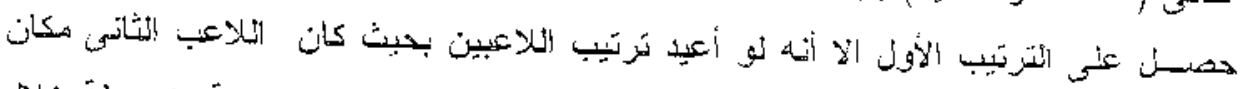

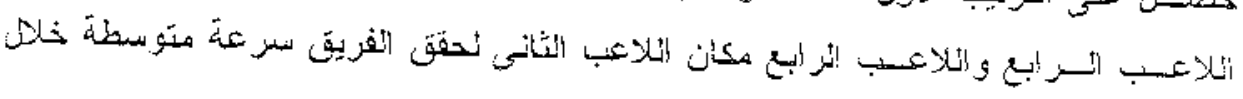




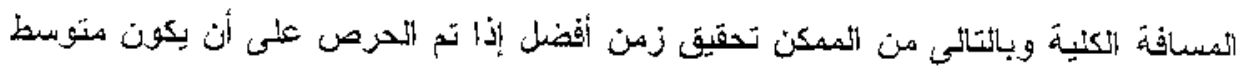

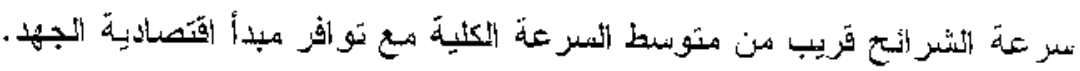

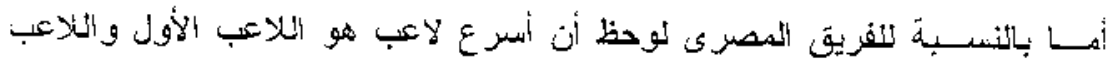

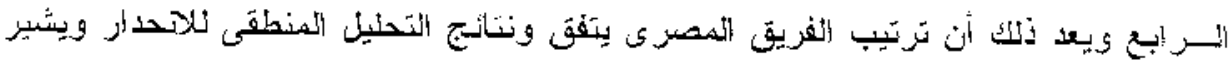

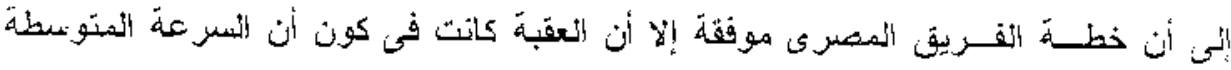

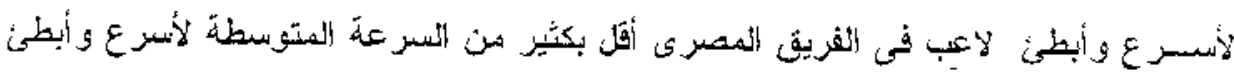

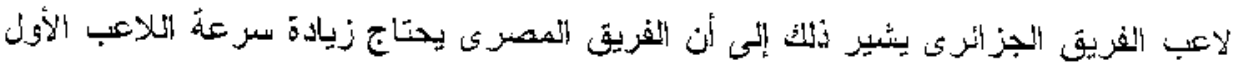

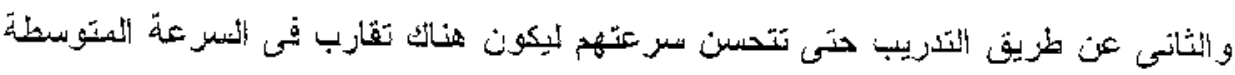

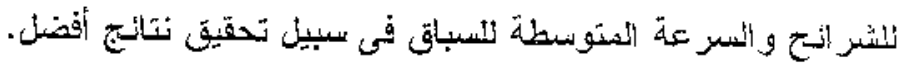

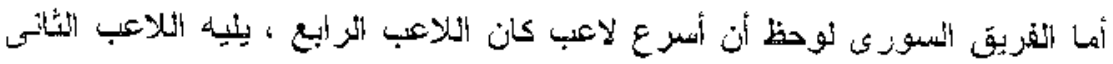

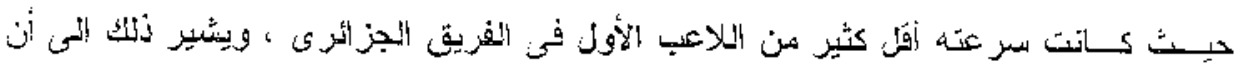

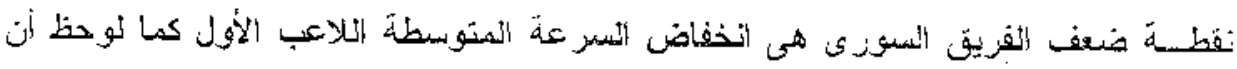

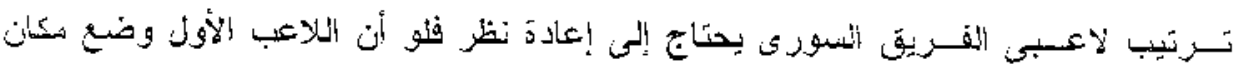

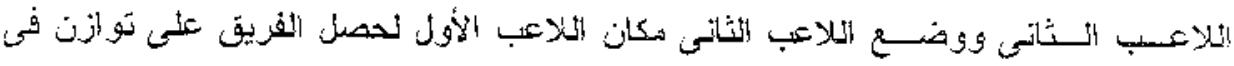

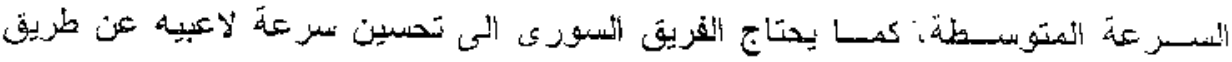

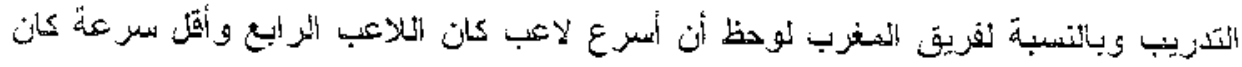

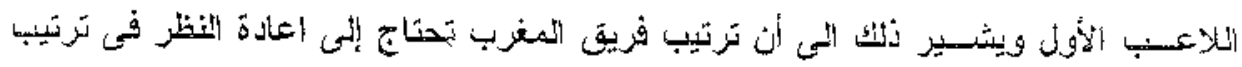

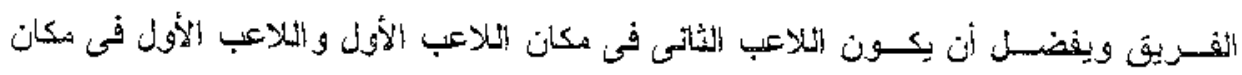

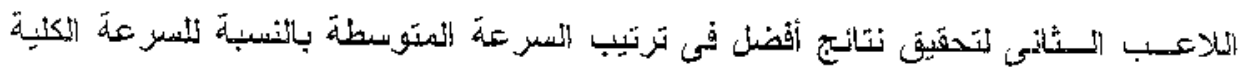

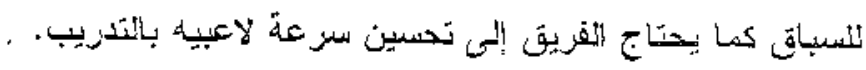

كمـا لوحظ أن أسرع لاعب فى سيلطنة عمان كان الملاعب الثخالث و أبطىئ لاعب كان

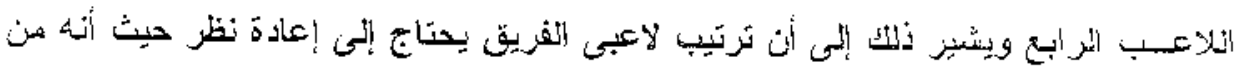

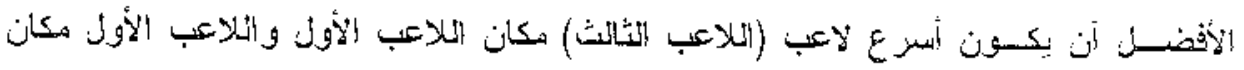

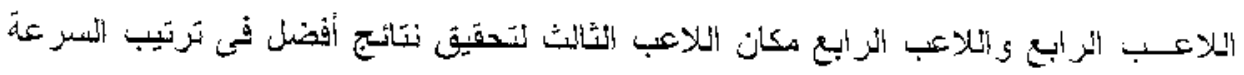

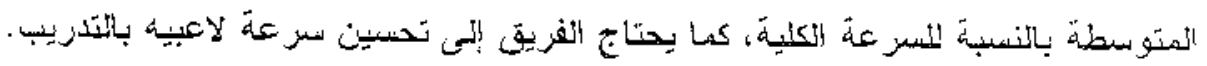


ويمكن تلخبص نقاط الضضعف في الثفرق المشتَركة كما يلئ :

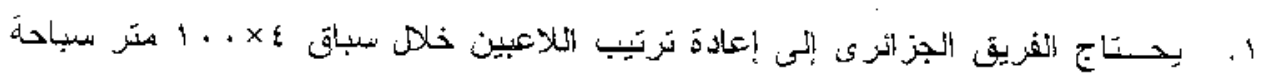

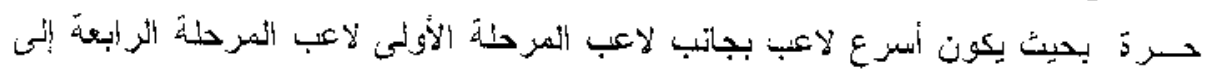

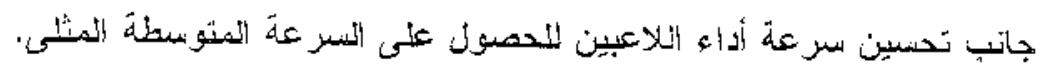

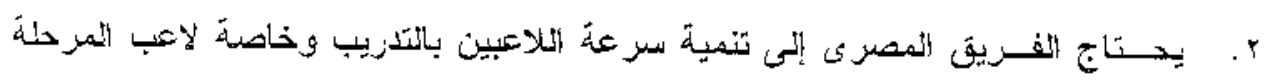

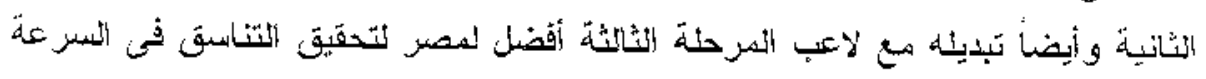
المصنو سطة.

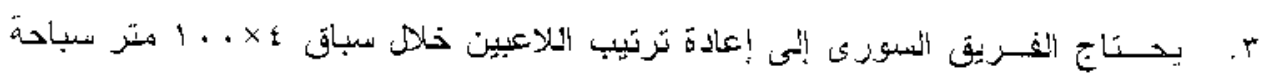

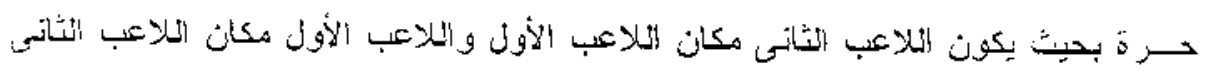

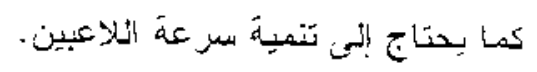

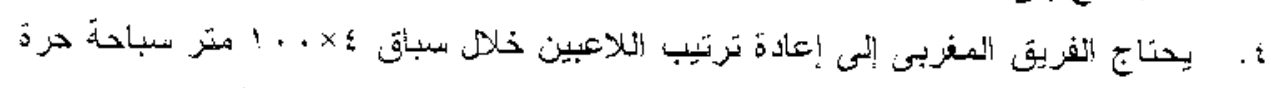

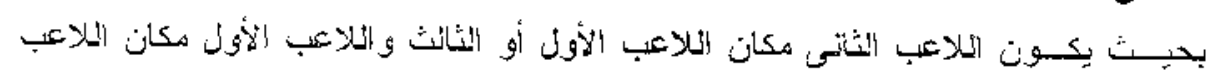

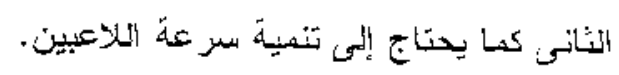

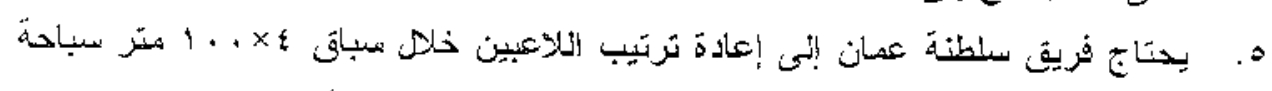

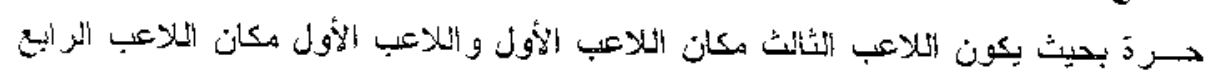

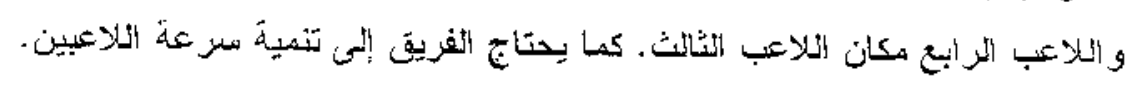

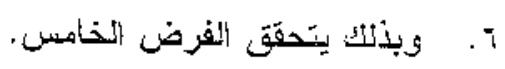

The Conclusions / / الاستخلاصنات

في حسود عينة البحت ودقة وسانل جمع البيانات و النتاثج التَى توصل نها البحث

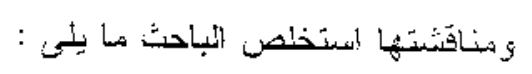

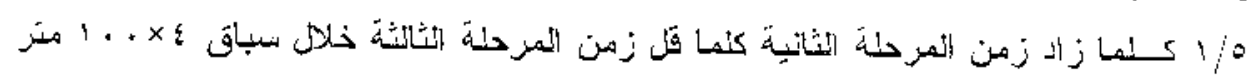
سباحة حرة

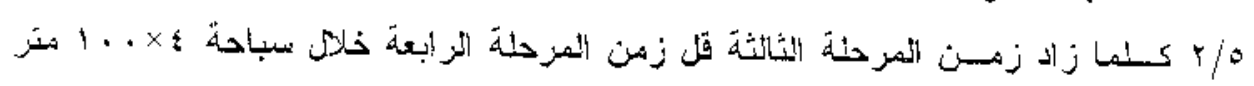

$$
\text { سباحة حرة. }
$$

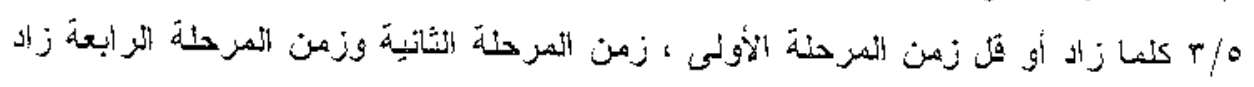

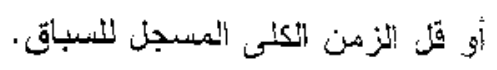




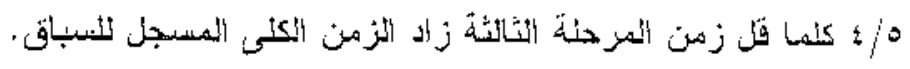

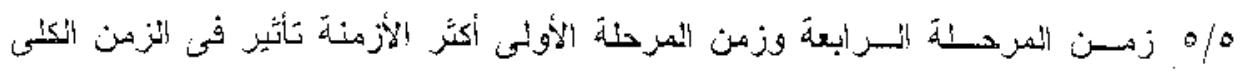
إلمسجل.

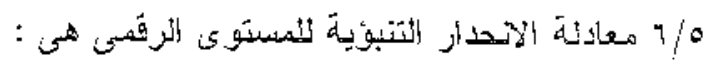

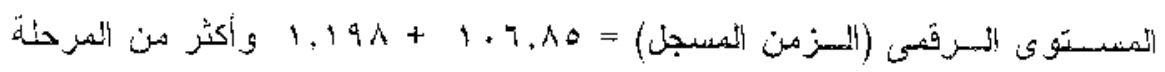

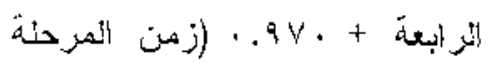

الأونىى)

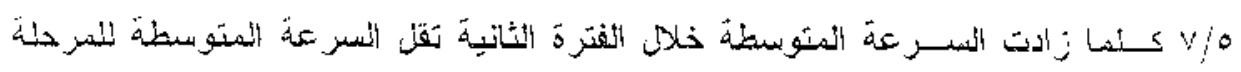
الثنائنة.

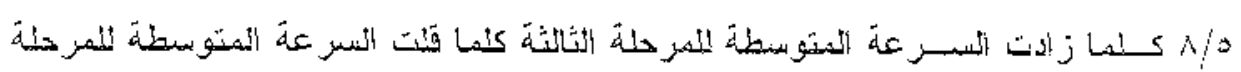

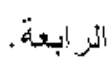

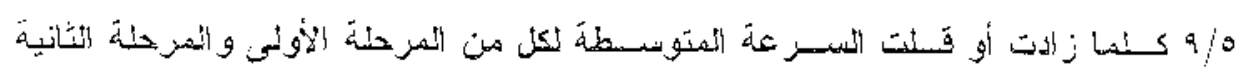

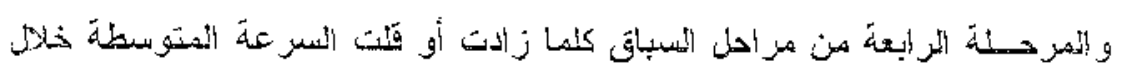

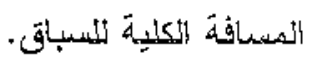

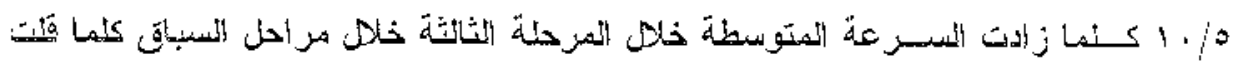

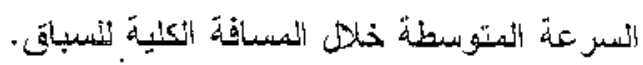

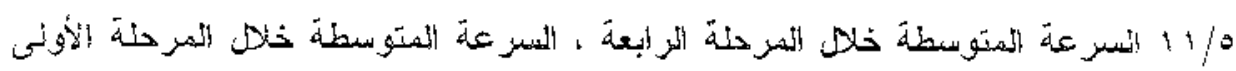

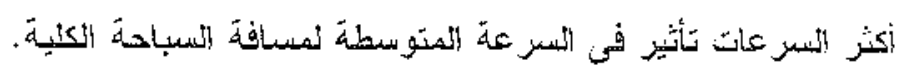

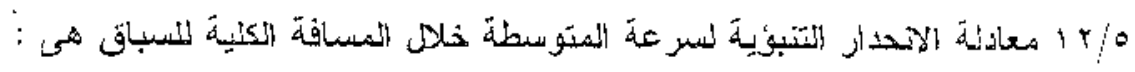

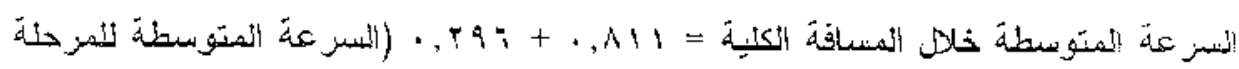

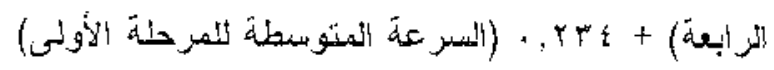

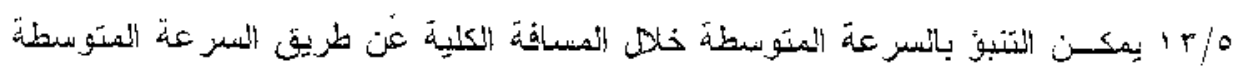

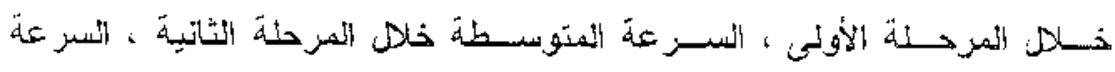

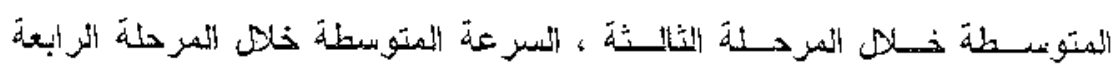

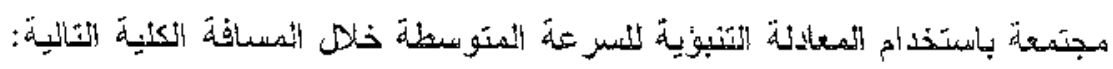




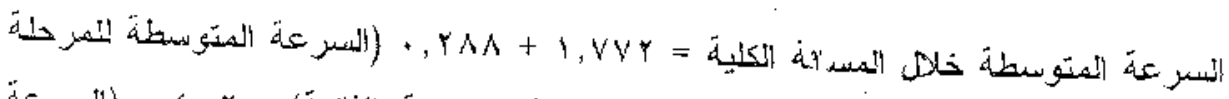

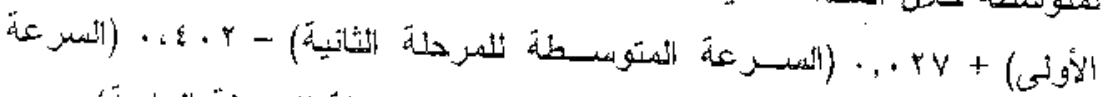

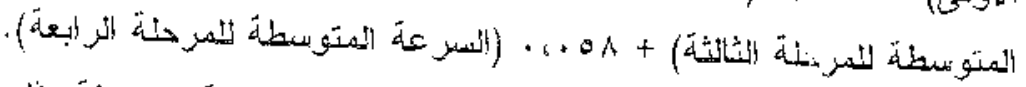

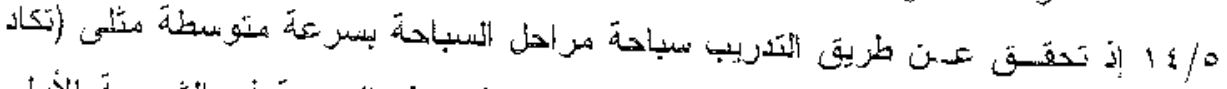

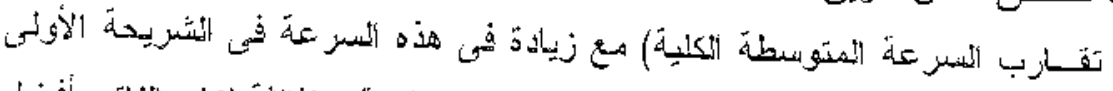

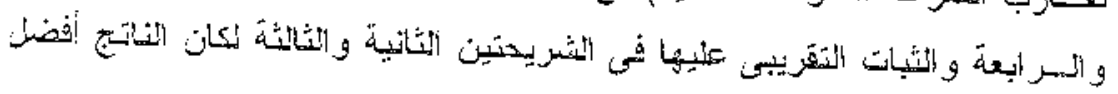

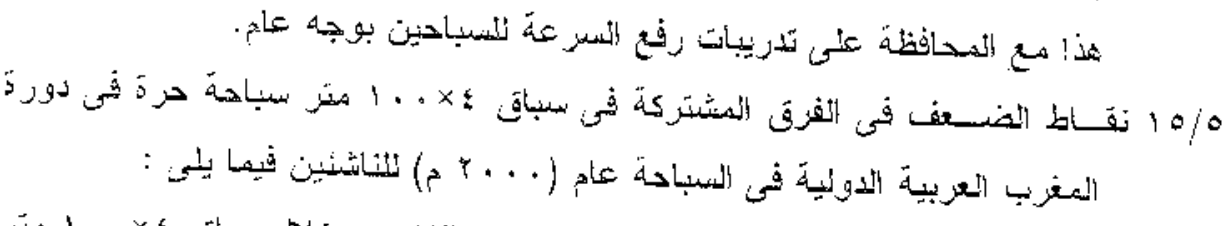

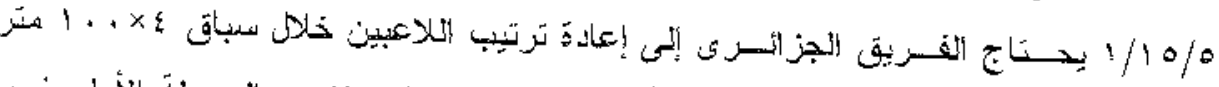

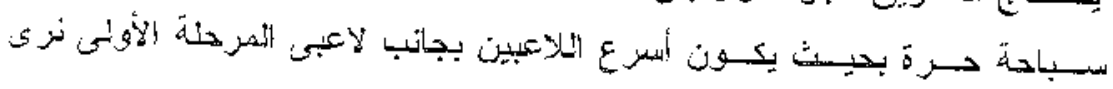

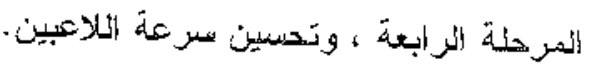

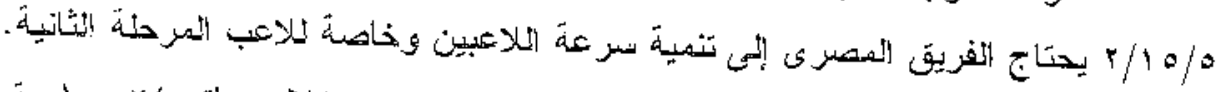

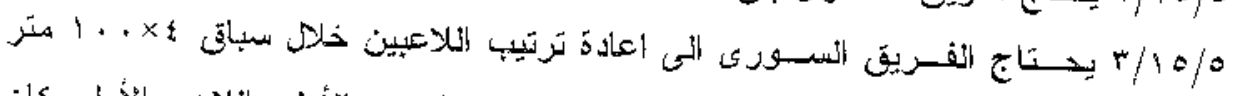

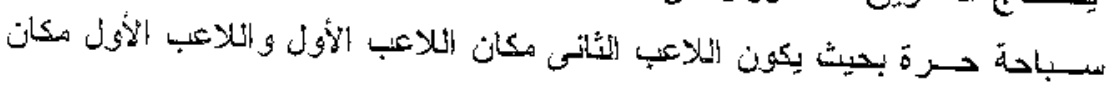

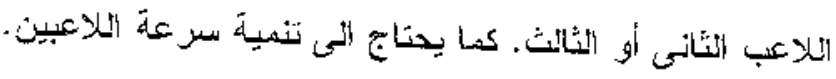

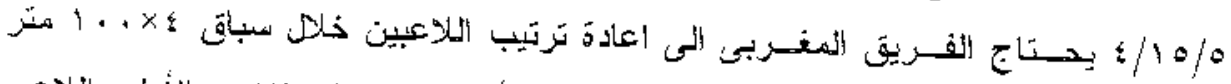

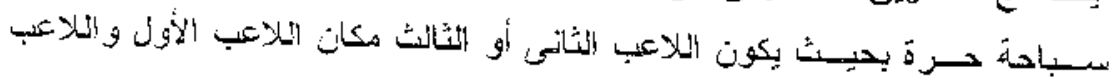

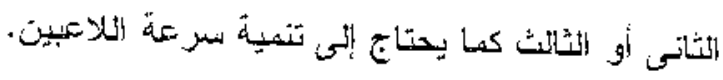

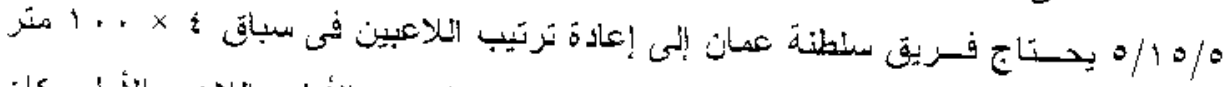

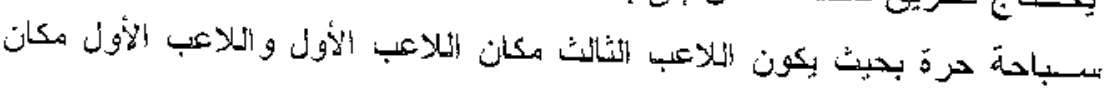

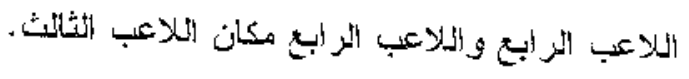

\section{The Recommendation التوصيات}

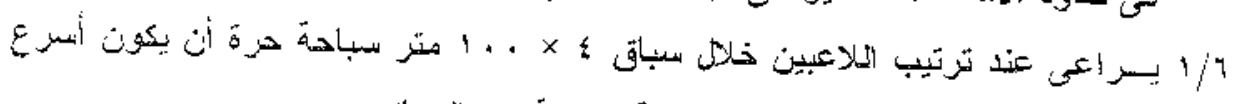

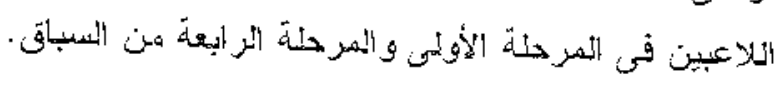




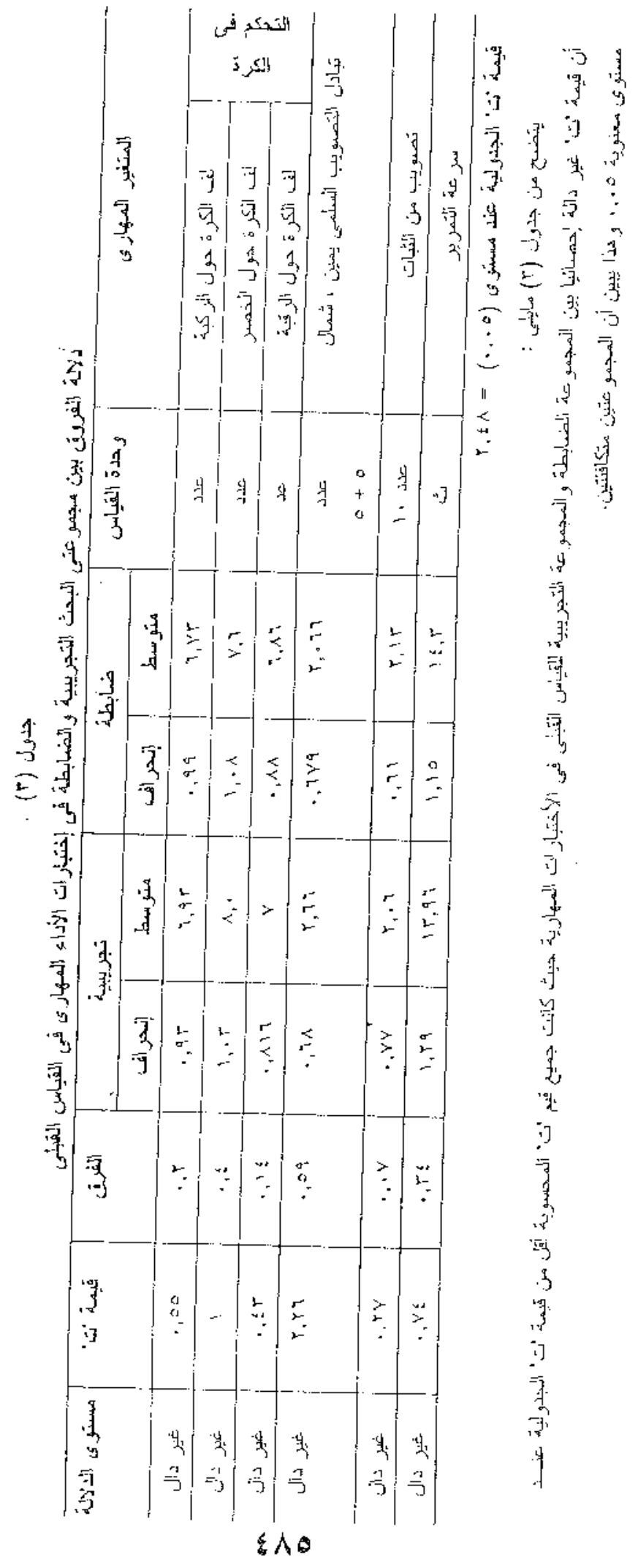




\section{ونسائل جبي البيانات}

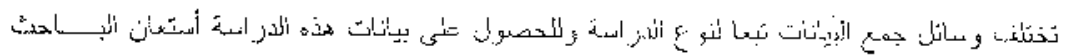

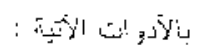

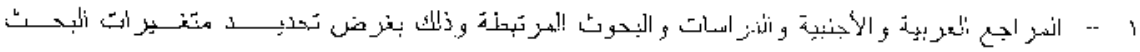

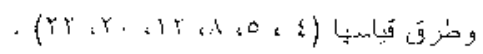

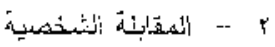

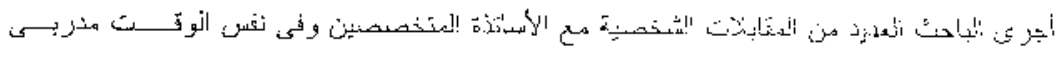

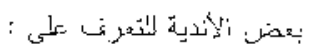

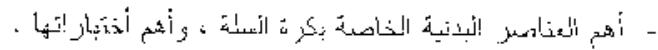

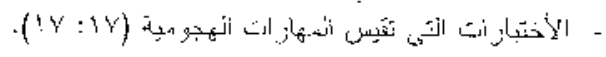

r

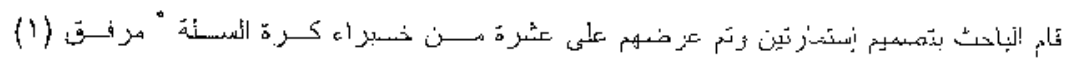

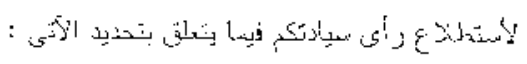

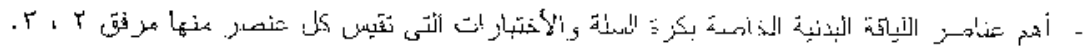

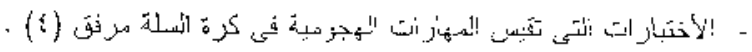

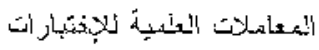

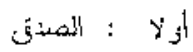

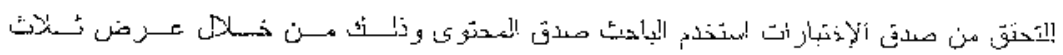

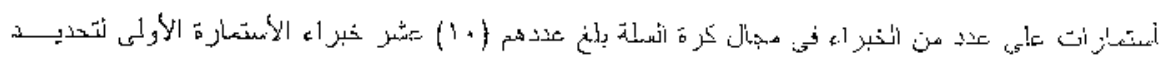

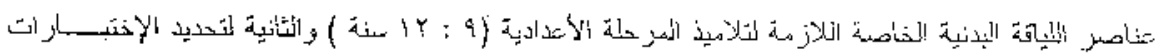

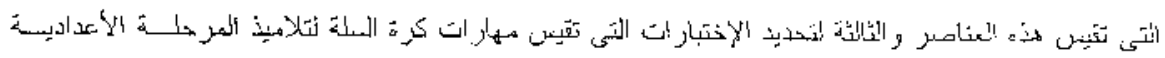

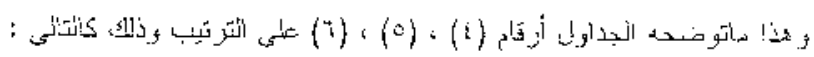
ا 1

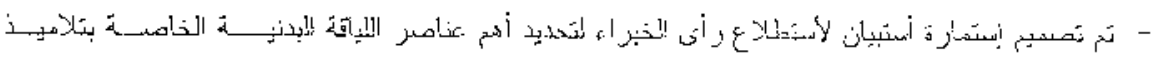

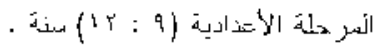

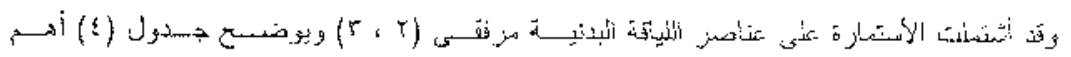

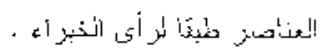

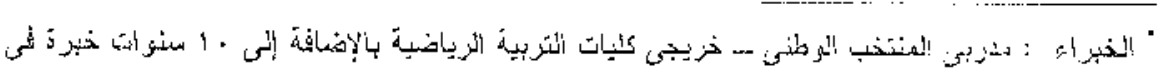

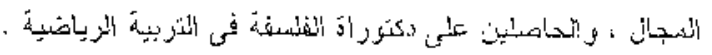




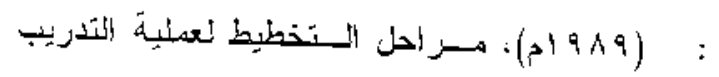

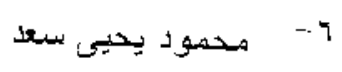

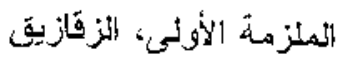

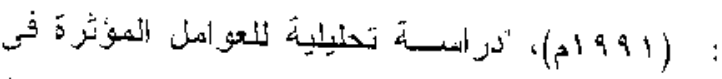

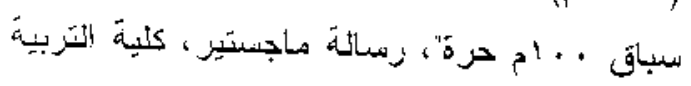

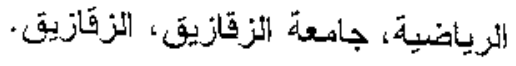

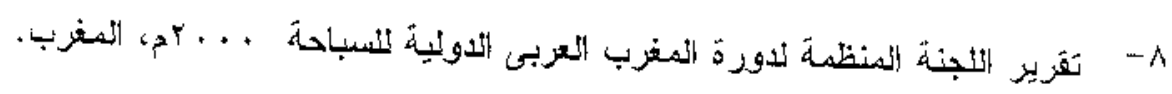

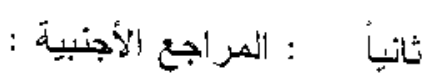

9. Councilman : (1977), Competitive swimming, Manual for coaches and swimmers, councilman, co. Blaomingtan.

10. East, D.

: (1970), Swimming an Analysis for stroke frequency, stroke length and performance, Journal of Health physical Education and Recreation No. 2, New Zealand. 